Article

\title{
New Discorhabdin Alkaloids from the Antarctic Deep-Sea Sponge Latrunculia biformis
}

\author{
Fengjie Li ${ }^{1}$, Christian Peifer ${ }^{2}$, Dorte Janussen ${ }^{3}$ and Deniz Tasdemir $1,4, * \mathbb{C}$ \\ 1 GEOMAR Centre for Marine Biotechnology (GEOMAR-Biotech), Research Unit Marine Natural Products \\ Chemistry, GEOMAR Helmholtz Centre for Ocean Research Kiel, Am Kiel-Kanal 44, 24106 Kiel, Germany \\ 2 Pharmaceutical Chemistry, Kiel University, Gutenbergstraße 76, 24118 Kiel, Germany \\ 3 Senckenberg Research Institute and Natural History Museum, Senckenberganlage 25, \\ D-60325 Frankfurt, Germany \\ 4 Faculty of Mathematics and Natural Sciences, Kiel University, Christian-Albrechts-Platz 4, \\ 24118 Kiel, Germany \\ * Correspondence: dtasdemir@geomar.de; Tel.: +49-431-600-4430
}

Received: 14 June 2019; Accepted: 22 July 2019; Published: 25 July 2019

\begin{abstract}
The sponge genus Latrunculia is a prolific source of discorhabdin type pyrroloiminoquinone alkaloids. In the continuation of our research interest into this genus, we studied the Antarctic deep-sea sponge Latrunculia biformis that showed potent in vitro anticancer activity. A targeted isolation process guided by bioactivity and molecular networking-based metabolomics yielded three known discorhabdins, (-)-discorhabdin L (1), (+)-discorhabdin A (2), (+)-discorhabdin Q (3), and three new discorhabdin analogs (-)-2-bromo-discorhabdin D (4), (-)-1-acetyl-discorhabdin L (5), and (+)-1-octacosatrienoyl-discorhabdin $\mathrm{L}(6)$ from the $\mathrm{MeOH}$-soluble portion of the organic extract. The chemical structures of 1-6 were elucidated by extensive NMR, HR-ESIMS, FT-IR, $[\alpha]_{D}$, and ECD (Electronic Circular Dichroism) spectroscopy analyses. Compounds 1, 5, and $\mathbf{6}$ showed promising anticancer activity with $\mathrm{IC}_{50}$ values of $0.94,2.71$, and $34.0 \mu \mathrm{M}$, respectively. Compounds 1-6 and the enantiomer of $\mathbf{1}((+)$-discorhabdin $\mathrm{L}, \mathbf{1 e})$ were docked to the active sites of two anticancer targets, topoisomerase I-II and indoleamine 2,3-dioxygenase (IDO1), to reveal, for the first time, the binding potential of discorhabdins to these proteins. Compounds $\mathbf{5}$ and $\mathbf{6}$ are the first discorhabdin analogs with an ester function at $\mathrm{C}-1$ and $\mathbf{6}$ is the first discorhabdin bearing a long-chain fatty acid at this position. This study confirms Latrunculia sponges to be excellent sources of chemically diverse discorhabdin alkaloids.
\end{abstract}

Keywords: Latrunculia; Antarctica; deep-sea sponge; molecular networking; molecular docking; discorhabdin

\section{Introduction}

Latrunculia species are cold-adapted sponges commonly found in the coastlines of the southern hemisphere [1-3]. The genus Latrunculia has proven to be a prolific source of structurally intriguing compounds from different classes, such as norsesterterpenes [4,5], callipeltins [6,7], and various types of pyrroloiminoquinone alkaloids [8-10]. Discorhabdins represent a large and unique subclass of pyrroloiminoquinone alkaloids that have been associated with the chemical defense and greenish to brownish coloration of the sponge [11,12]. Discorhabdins exhibit strong anticancer activity against many cancer types, such as human colon cancer, adenocarcinoma, and leukemia [13-15]. However, the mechanism of their anticancer action has been poorly studied. Indeed, only the farnesyltransferase enzyme [16] and hypoxia-inducible factor $1 \alpha$ (HIF-1 $\alpha)$ and transcriptional coactivator p300 interaction [17] have been shown as potential targets of discorhabdins. 
As part of our research interest into deep-sea Latrunculia sponges from Antarctica [18], herein we investigated the in-depth chemistry of Latrunculia biformis, which was collected from the Antarctic Weddell Sea shelf at $291 \mathrm{~m}$ depth. The crude organic extract of the sponge exhibited significant in vitro anticancer activity against six cancer cell lines. A molecular networking (MN)-based metabolomics study on fractions obtained from the $\mathrm{MeOH}$-soluble portion of the sponge indicated the presence of a large discorhabdin cluster with many nodes belonging to potentially new discorhabdins. Guided by anticancer activity and MN-based dereplication, six discorhabdin-type alkaloids were isolated from the $\mathrm{MeOH}$ subextract, including three known compounds (-)-discorhabdin L (1), (+)-discorhabdin A (2), (+)-discorhabdin $\mathrm{Q}(3)$ and three new discorhabdin derivatives, namely (-)-2-bromo-discorhabdin $\mathrm{D}$ (4), (-)-1-acetyl-discorhabdin L (5), and (+)-1-octacosatrienoyl-discorhabdin L (6). Since the amounts of the isolated compounds were very minor, only compounds 1, 5 and $\mathbf{6}$ could be tested for their anticancer activity against the human colon cancer cell line HCT-116. We applied a structure-based docking approach on all isolated compounds and the enantiomer of $\mathbf{1}$ (1e) against two cancer targets reported for pyrroloiminoquinone alkaloids, i.e., topoisomerase I-II and indoleamine 2,3-dioxygenase IDO1 [19-21] to predict their anticancer potential and to suggest potential molecular mechanism(s) of action. This study reports MN and bioactivity-guided isolation of compounds 1-6, their structure elucidation, and biological activities with potential target identification for their anticancer activity.

\section{Results}

\subsection{Bioactivity and Molecular Networking-guided Purification and Structural Elucidation}

The olive green-colored sponge material was freeze-dried and successively extracted with water, $\mathrm{MeOH}$, and dichloromethane (DCM) subsequently. The combined organic extract was submitted to bioactivity screening against six cancer cell lines, where it showed significant activity with $\mathrm{IC}_{50}$ values ranging from 4.0 to $56.2 \mu \mathrm{g} / \mathrm{mL}$ (Table 1). The solvent partitioning of the crude organic extract between $\mathrm{MeOH}$ and $n$-hexane yielded the $\mathrm{MeOH}(\mathrm{M})$ and the $n$-hexane subextracts. The $\mathrm{M}$ subextract demonstrated strong anticancer activity (Figure 1) and was further fractionated over a C18 SPE cartridge. The anticancer activity was tracked to six SPE fractions, M2-M5, M7, and M8 (Figure 1).

Table 1. Anticancer activity of the L. biformis crude extract. The $\mathrm{IC}_{50}$ values are in $\mu \mathrm{g} / \mathrm{mL}$. Positive control doxorubicine.

\begin{tabular}{ccccccc}
\hline Sample & A-375 & HCT-116 & A-549 & MB-231 & Hep G2 & HT-29 \\
\hline Crude extract & 17.4 & 4.8 & 56.2 & 46.8 & 18.2 & 4.0 \\
Positive control & 0.13 & 10.6 & 31.4 & 15.2 & 14.6 & 3.0 \\
\hline
\end{tabular}

In order to prioritize the isolation workflow towards undescribed molecules with potential anticancer properties, we acquired tandem UPLC-QToF-MS/MS (positive-ion mode) data on these six active fractions. The generated MS/MS (MS') data were uploaded to the publicly available Global Natural Product Social Molecular Networking (GNPS) platform (http://gnps.ucsd.edu) and analyzed following the molecular networking (MN) online workflow [22]. Software Cytoscape (Version 3.61) was used to visualize the resulting networks. The automated dereplication on GNPS platform did not annotate any pyrroloiminoquinone alkaloids. Hence, compound annotation was based on manual dereplication by comparing the predicted molecular formulae against multiple public or commercially available databases. 


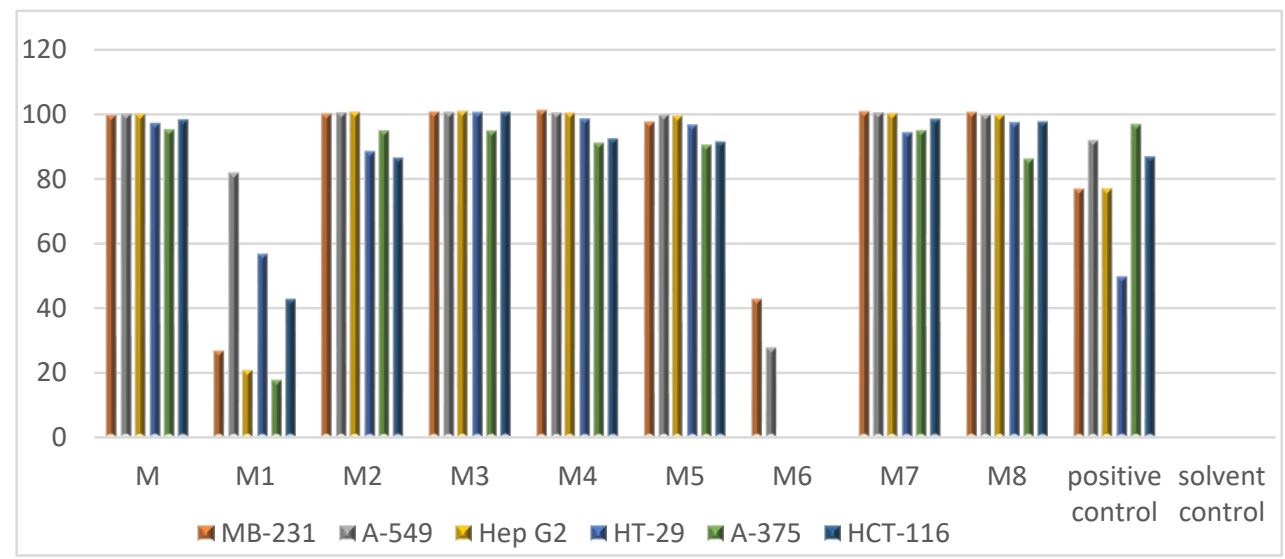

Figure 1. In vitro activity of $\mathrm{MeOH}$ subextract $(\mathrm{M})$ and its $\mathrm{C} 18$ solid phase extraction (SPE) fractions (M1-M8) against six cancer cell lines. Test concentration: $100 \mu \mathrm{g} / \mathrm{mL}$. Positive control: Doxorubicine. Solvent control: $0.5 \%$ DMSO.

After a comprehensive examination of the global MN of the SPE fractions, two clusters attracted our attention (Figure 2). Cluster 1 contained five nodes, four of which were annotated as known molecules discorhabdin L [13], its analog, discorhabdin D [23], and 1-methoxydiscorhabdin D [19], leaving the node at $\mathrm{m} / \mathrm{z} 368.0380$ to be a putatively new derivative (Figure 2). From this cluster, we were able to purify (-)-discorhabdin L (1), but failed to purify the potentially new discorhabdin analog $(\mathrm{m} / \mathrm{z}$ 368.0380) due to its very minor quantity.

With 21 nodes, cluster 2 was the biggest in the generated MN, which can be further divided into three subclusters (Figure 2). Based on the elemental composition analysis, MS/MS fragmentation patterns, and biological source, two brominated alkaloids discorhabdin A [24] and discorhabdin G [25] were identified in subcluster 3. However, only discorhabdin A (2) was isolated in sufficient amounts for NMR and other spectroscopic analyses. Discorhabdin H2 [26] was the only annotated compound in subcluster 2. Unfortunately, neither this compound nor the remaining nodes that represent potentially new discorhabdin analogs could be purified in sufficient quantity.

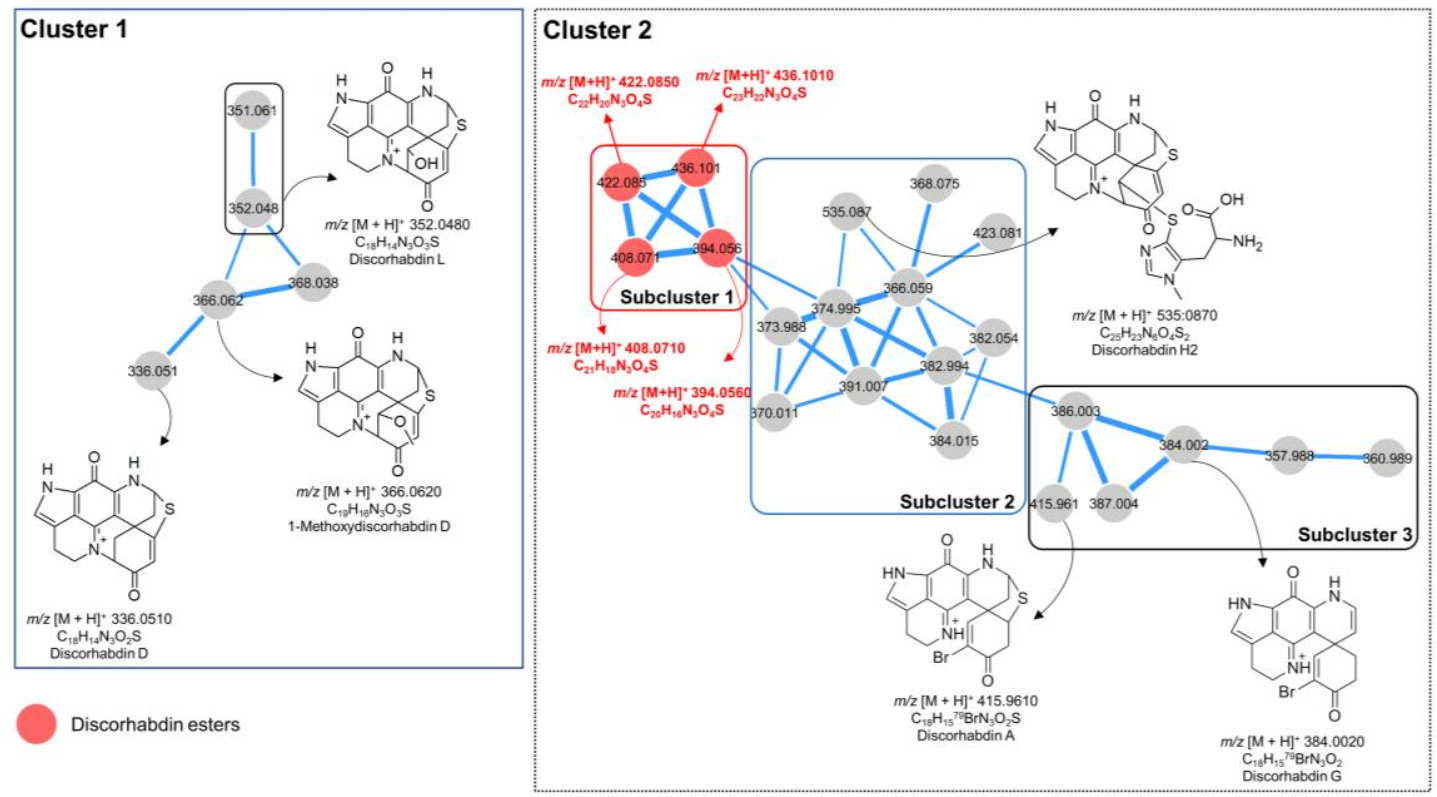

Figure 2. Molecular cluster observed in SPE fractions of L. biformis $\mathrm{MeOH}$ subextract. Numbers within the nodes indicate parent ions, and edge thickness represents the cosine similarity between nodes. Red nodes: Discorhabdin esters; Grey nodes: Other discorhabdin analogs. 
The subcluster 1 (of cluster 2) contained four nonbrominated nodes at $\mathrm{m} / \mathrm{z} 394.0560,408.0710$, 422.085, and 436.1010 connected with thick edges, indicating their high structural similarity. Elemental composition analysis revealed the difference of a $\mathrm{CH}_{2}$ unit between these ions (Figure 2, in red). In-depth analysis of their MS/MS spectra revealed the presence of the same MS fragment $(\mathrm{m} / \mathrm{z} 352.0766$, $\mathrm{C}_{18} \mathrm{H}_{14} \mathrm{~N}_{3} \mathrm{O}_{3} \mathrm{~S}$ ) in all four compounds, suggesting these compounds to be discorhabdin alkaloids bearing an alkyl chain with varying lengths. From subcluster 1, we isolated the compound with $\mathrm{m} / \mathrm{z} 394.0560$ and identified it as a new metabolite, (-)-1-acetyl-discorhabdin L (5), as discussed later.

In addition, we purified three compounds, namely the known compound (+)-discorhabdin Q (3) as well as two new compounds, namely (-)-2-bromo-discorhabdin D (4) and (+)-1-octacosatrienoyl-discorhabdin L (6), which did not appear in the MN because of the low intensity of their MS fragments. The enantiopurity of all purified compounds was further checked individually by RP-DAD-HPLC on an analytical chiral column. The sharp single peak in the UV chromatograms confirmed the enantiopurity of 1-6.

The structure of compound 1 was elucidated as $(-)-(1 R, 2 S, 6 R, 8 S)$-discorhabdin L [13], based on comparison of its 1D and 2D NMR data including NOESY spectrum (Tables 2 and 3, Supplementary Figures S1-S6). The specific rotation of compound $\mathbf{1}\left([\alpha]^{20}{ }_{\mathrm{D}}=-71, c 0.1, \mathrm{MeOH}\right)$ showed the same sign as that reported for (-)-discorhabdin $\mathrm{L}\left([\alpha]^{20}{ }_{\mathrm{D}}=-240, c 0.0125, \mathrm{MeOH}\right)$ [26]. In order to confirm the absolute configuration of compound 1, the ECD (Electronic Circular Dichroism) spectrum was run. The experimental ECD spectrum of 1 (Supplementary Figure S8) was essentially identical to the ECD spectrum of $(-)-(1 R, 2 S, 6 R, 8 S)$-discorhabdin L [26]. Hence, compound 1 was unambiguously characterized as $(-)-(1 R, 2 S, 6 R, 8 S)$-discorhabdin $\mathrm{L}$.

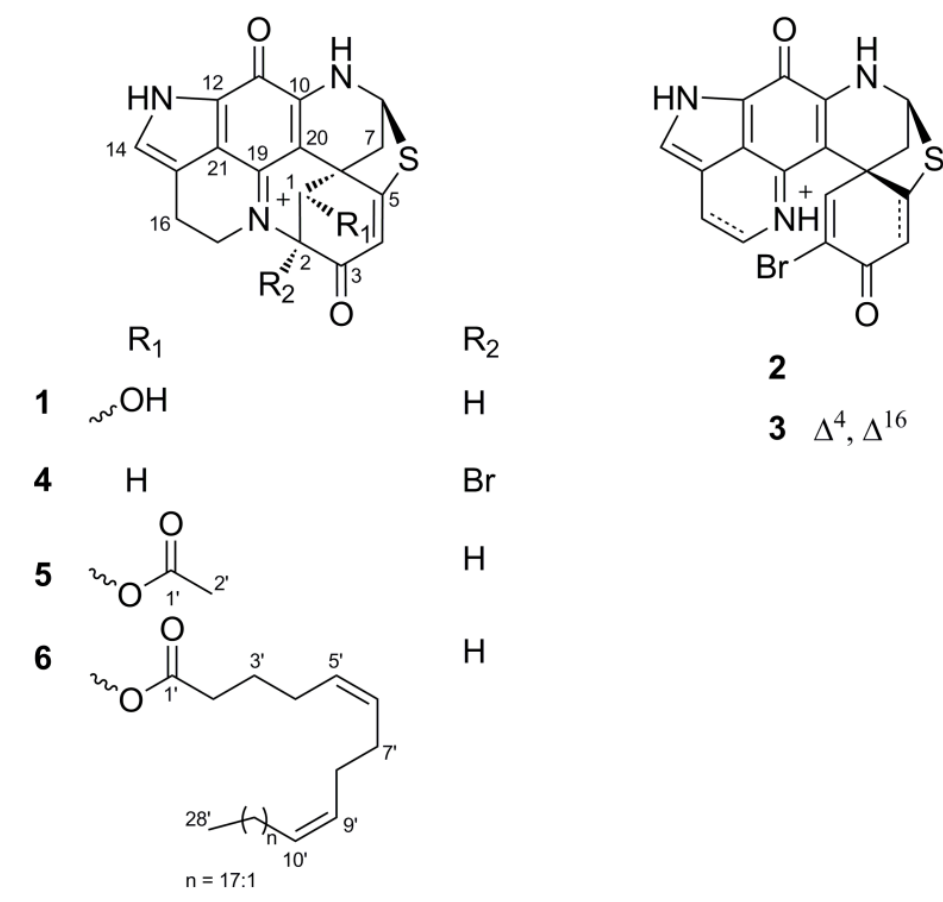

Figure 3. Chemical structures of compounds 1-6.

Compound 2 exhibited the same ${ }^{1} \mathrm{H}$ and ${ }^{13} \mathrm{C}$ NMR resonances (Supplementary Figures S9 and S10) as (+)-discorhabdin A [24,27]. The analysis of its COSY, HSQC, and HMBC spectra (Supplementary Figures S10-S12) supported the same planar structure as discorhabdin A and NOESY spectrum confirmed the relative configuration of three stereocenters (Supplementary Figure S13). The specific rotation of compound $2\left([\alpha]^{20} \mathrm{D}=+197, c 0.01, \mathrm{MeOH}\right)$ exhibited the same sign as (+)-discorhabdin A $\left([\alpha]^{20}{ }_{\mathrm{D}}=+400, c 0.05, \mathrm{MeOH}\right)[24]$. An early X-ray crystal analysis has confirmed the configuration of 
the chiral centers within (+)-discorhabdin $\mathrm{A}$ as $5 R, 6 S, 8 S$ [27]. Thus, compound 2 was identified as $(+)-(5 R, 6 S, 8 S)$-discorhabdin A (Figure 3).

Compound 3 was identified as the known compound discorhabdin $Q$, based on its 1D and 2D NMR data (Supplementary Figures S15-S20), which were in good agreement with those reported in the literature [26]. The examination of the ${ }^{1} \mathrm{H}-{ }^{1} \mathrm{H}$ NOESY spectrum of 3 (Supplementary Figure S19) allowed the assignment of the relative configuration of two stereocenters. Compound 3 exhibited a specific rotation value $\left([\alpha]^{20} \mathrm{D}=+568, c 0.1, \mathrm{MeOH}\right)$, which was similar both in the magnitude and sign to that observed for $(+)-(6 S, 8 S)$-discorhabdin $\mathrm{Q}\left([\alpha]^{20} \mathrm{D}=+720, c 0.025, \mathrm{MeOH}\right)[26]$, hence we concluded compound 3 as $(+)-(6 S, 8 S)$-discorhabdin $Q$.

Table 2. ${ }^{1} \mathrm{H}$ NMR data of compounds $\mathbf{1 , 4}, \mathbf{5}$, and $\mathbf{6}$ in $\mathrm{CD}_{3} \mathrm{OD}$ (trifluoroacetic acid (TFA) salts, $600 \mathrm{MHz}$, $\delta$ in ppm).

\begin{tabular}{|c|c|c|c|c|}
\hline \multirow{2}{*}{ NO. } & 1 & 4 & 5 & 6 \\
\hline & $\delta_{\mathrm{H}}$, Mult. $(J$ in $\mathrm{Hz})$ & $\delta_{\mathrm{H}}$, Mult. $(J$ in $\mathrm{Hz})$ & $\delta_{\mathrm{H}}$, Mult. $(J$ in $\mathrm{Hz})$ & $\delta_{\mathrm{H}}$, Mult. $(J$ in $\mathrm{Hz})$ \\
\hline 1 & $4.63 \mathrm{~d}(3.6)$ & $3.58 \mathrm{~d}(13.3)$ & $5.79 \mathrm{~d}(3.6)$ & $5.79 \mathrm{~d}(3.6)$ \\
\hline 2 & $4.15 \mathrm{~d}(3.6)$ & $\begin{array}{c}- \\
0.204(10.0)\end{array}$ & $4.36 \mathrm{~d}(3.6)$ & $4.35 \mathrm{~d}(3.6)$ \\
\hline 4 & $6.14 \mathrm{~s}$ & $6.14 \mathrm{~s}$ & $6.23 \mathrm{~s}$ & $6.23 \mathrm{~s}$ \\
\hline $7 \alpha$ & $2.57 \mathrm{dd}(1.3,12.0)$ & $2.66 \mathrm{dd}(1.5,12.1)$ & $2.63 \mathrm{dd}(1.4,12.1)$ & $2.64 \mathrm{~d}(1.2,12.1)$ \\
\hline $7 \beta$ & $2.96 \mathrm{dd}(3.6,12.0)$ & $2.84 \mathrm{dd}(3.5,12.1)$ & $2.81 \mathrm{dd}(3.7,12.1)$ & $2.76 \mathrm{dd}(3.6,12.1)$ \\
\hline 8 & $5.59 \mathrm{dd}(1.3,3.6)$ & $5.68 \mathrm{dd}(1.5,3.5)$ & $5.61 \mathrm{dd}(1.4,3.7)$ & $5.61 \mathrm{dd}(1.2,3.6)$ \\
\hline 14 & $7.11 \mathrm{~s}$ & $7.14 \mathrm{~s}$ & $7.13 \mathrm{~s}$ & $7.13 \mathrm{~s}$ \\
\hline \multirow{2}{*}{16} & $3.19 \mathrm{ddd}(7.5,13.0,16.7)$ & \multirow{2}{*}{$3.10 \mathrm{~m}$} & $3.21 \mathrm{ddd}(6.9,7.5,16.6)$ & $3.22 \mathrm{ddd}(6.8,7.3,16.6)$ \\
\hline & 3.06 ddd $(3.0,6.9,16.7)$ & & 3.08 ddd $(2.9,6.9,16.6)$ & 3.08 ddd $(2.7,6.8,16.6)$ \\
\hline \multirow[t]{2}{*}{17} & 4.02 ddd $(3.0,7.5,14.2)$ & 4.62 ddd $(2.1,5.6,13.8)$ & 4.04 ddd $(2.9,7.5,13.8)$ & 4.04 ddd $(2.7,7.3,13.7)$ \\
\hline & $3.91 \mathrm{ddd}(6.9,13.0,14.2)$ & $3.66 \mathrm{td}(6.3,13.8)$ & $3.93 \mathrm{td}(6.9,13.8)$ & $3.93 \mathrm{td}(6.8,13.7)$ \\
\hline $2^{\prime}$ & - & - & $2.15 \mathrm{~s}$ & $2.44 \operatorname{td}(1.5,7.5)$ \\
\hline $3^{\prime}$ & - & - & - & $1.69 \mathrm{~m}$ \\
\hline $4^{\prime}$ & - & - & - & $2.10 \mathrm{~m}$ \\
\hline $5^{\prime}$ & - & - & - & $5.34 \mathrm{~m}$ \\
\hline $6^{\prime}$ & - & - & - & $5.44 \mathrm{~m}$ \\
\hline $7^{\prime}$ & - & - & - & $2.08 \mathrm{~m}$ \\
\hline $8^{\prime}$ & - & - & - & $2.08 \mathrm{~m}$ \\
\hline $9^{\prime}$ & - & - & - & $5.37 \mathrm{~m}$ \\
\hline $10^{\prime}$ & - & - & - & $5.34 \mathrm{~m}$ \\
\hline $11^{\prime}-27^{\prime}$ & - & - & - & $\begin{array}{c}1.25-1.40 \mathrm{~m} ; \\
2.00-2.06 \mathrm{~m} ; 5.36 \mathrm{~m}\end{array}$ \\
\hline $28^{\prime}$ & - & - & - & $0.90 \mathrm{t}(7.0)$ \\
\hline
\end{tabular}

Compound 4 was obtained as a greenish film. The isotopic pattern of the molecule ion peaks (1:1 ratio) was indicative for the presence of one bromine atom in this molecule. The molecular formula of $\mathrm{C}_{18} \mathrm{H}_{13}{ }^{79} \mathrm{BrN}_{3} \mathrm{O}_{2} \mathrm{~S}$ was established by the pseudo-molecular ion peak at $m / z 413.9913[\mathrm{M}+\mathrm{H}]^{+}$in the HR-ESIMS (Supplementary Figure S27) spectrum, requiring 14 degrees of unsaturation. The ${ }^{1} \mathrm{H}$ NMR data (Table 2, Supplementary Figure S22) together with HSQC spectrum (Supplementary Figure S23) revealed the presence of three methine resonances at $\delta_{\mathrm{H}} 7.14(\mathrm{H}-14, \mathrm{~s}), \delta_{\mathrm{H}} 6.14(\mathrm{H}-4, \mathrm{~s})$, and $\delta_{\mathrm{H}} 5.68(\mathrm{H}-8$, $\mathrm{dd}, J=1.5,3.5 \mathrm{~Hz})$, four methylene groups corresponding to $\mathrm{H}_{2}-17\left(\delta_{\mathrm{H}} 3.66\right.$ and 4.62$), \mathrm{H}_{2}-1\left(\delta_{\mathrm{H}} 3.23\right.$ and 3.58), $\mathrm{H}_{2}-16\left(\delta_{\mathrm{H}} 3.10\right)$, and $\mathrm{H}_{2}-7\left(\delta_{\mathrm{H}} 2.66\right.$ and 2.84). The ${ }^{13} \mathrm{C}$ NMR spectrum (Table 3$)$ showed 18 carbon signals including 4 methylenes $\left(\delta_{C} 20.0,38.7,42.4\right.$, and 50.2), 3 methines $\left(\delta_{C} 63.1,110.9\right.$, and 126.0), and 11 quaternary carbons $\left(\delta_{C} 44.5,78.1,100.4,119.3,122.2,124.0,148.2,150.2,165.4,172.8\right.$, and 176.4). By comparison with the data reported for discorhabdins [13,23], the three low-field quaternary carbon signals at $\delta_{C} 176.4,172.8$, and 165.4 were tentatively assigned to C-3, C-5, and C-11, respectively, while the high-field quaternary carbon at $\delta_{\mathrm{C}} 44.5$ was assigned to $\mathrm{C}-6$. The COSY correlation between $\mathrm{H}_{2}-16$ and $\mathrm{H}_{2}-17$, together with the additional ${ }^{1} \mathrm{H}-{ }^{13} \mathrm{C} \mathrm{HMBC}$ correlations between $\mathrm{H}-14 / \mathrm{C}-12, \mathrm{C}-21, \mathrm{C}-11$; $\mathrm{H}_{2}-16 / \mathrm{C}-14, \mathrm{C}-21 ; \mathrm{H}_{2}-17 / \mathrm{C}-15, \mathrm{C}-19$ confirmed the pyrroloiminoquinone motif [13,23]. Similarly, the homonuclear COSY correlation between $\mathrm{H}_{2}-7$ and $\mathrm{H}-8$, and the $\mathrm{HMBC}$ correlations between $\mathrm{H}_{2}-1 / \mathrm{C}-2$, $\mathrm{C}-3, \mathrm{C}-6, \mathrm{C}-20$; H-4/C-2, C-3, C-6; and $\mathrm{H}_{2}-7 / \mathrm{C}-5, \mathrm{C}-6, \mathrm{C}-20$ suggested the position of the carbonyl group 
$\left(\delta_{\mathrm{C}} 176.4\right)$ at $\mathrm{C}-3$, and the position of the methylene $\left(\delta_{\mathrm{C}} 42.4\right)$ at $\mathrm{C}-1$ (Figure $\left.4 \mathrm{~A}\right)$. A further HMBC coupling between $\mathrm{H}-8$ and $\mathrm{C}-5$ was indicative of a thioether bridge between $\mathrm{C}-8$ and $\mathrm{C}-5$, while the HMBC correlation between $\mathrm{H}_{2}-17$ and C-2 established the bridge between $\mathrm{N}-18$ and C-2 (Figure 4A). All these data, plus the lack of any further spin coupling observed for $\mathrm{H}_{2}-1$, allowed the placement of the bromine atom on the remaining quaternary carbon, $\mathrm{C}-2$. Thus the planar structure of compound 4 was elucidated as 2-bromo-discorhabdin D.

Table 3. ${ }^{13} \mathrm{C}$ NMR data of compounds $\mathbf{1}, \mathbf{4}, \mathbf{5}$, and $\mathbf{6}$ in $\mathrm{CD}_{3} \mathrm{OD}(150 \mathrm{MHz}, \delta$ in ppm).

\begin{tabular}{|c|c|c|c|c|}
\hline \multirow{2}{*}{ Position } & 1 & 4 & 5 & 6 \\
\hline & $\delta_{\mathrm{C}}$ & $\delta_{\mathrm{C}}{ }^{\mathrm{a}}$ & $\delta_{\mathrm{C}}$ & $\delta_{\mathrm{C}}$ \\
\hline 1 & $68.5(\mathrm{CH})$ & $42.4\left(\mathrm{CH}_{2}\right)$ & $69.6(\mathrm{CH})$ & $69.5(\mathrm{CH})$ \\
\hline 2 & $67.8(\mathrm{CH})$ & $78.1(\mathrm{C})$ & $64.6(\mathrm{CH})$ & $64.6(\mathrm{CH})$ \\
\hline 3 & $184.8(\mathrm{C})$ & $176.4(\mathrm{C})$ & $183.1(\mathrm{C})$ & $183.0(\mathrm{C})$ \\
\hline 4 & $114.1(\mathrm{CH})$ & $110.9(\mathrm{CH})$ & $114.4(\mathrm{CH})$ & $114.4(\mathrm{CH})$ \\
\hline 5 & $171.5(\mathrm{C})$ & $172.8(\mathrm{C})$ & $171.2(\mathrm{C})$ & $171.1(\mathrm{C})$ \\
\hline 6 & $48.6(\mathrm{C})$ & $44.5(\mathrm{C})$ & $47.0(\mathrm{C})$ & $47.1(\mathrm{C})$ \\
\hline 7 & $37.4\left(\mathrm{CH}_{2}\right)$ & $38.7\left(\mathrm{CH}_{2}\right)$ & $37.4\left(\mathrm{CH}_{2}\right)$ & $37.5\left(\mathrm{CH}_{2}\right)$ \\
\hline 8 & $63.7(\mathrm{CH})$ & $63.1(\mathrm{CH})$ & $63.5(\mathrm{CH})$ & $63.5(\mathrm{CH})$ \\
\hline 10 & $148.6(\mathrm{C})$ & $148.2(\mathrm{C})$ & $149.0(\mathrm{C})$ & $149.1(\mathrm{C})$ \\
\hline 11 & $167.5(\mathrm{C})$ & $165.4(\mathrm{C})$ & $167.1(\mathrm{C})$ & $167.1(\mathrm{C})$ \\
\hline 12 & $125.6(\mathrm{C})$ & $124.0(\mathrm{C})$ & $125.6(\mathrm{C})$ & $125.6(\mathrm{C})$ \\
\hline 14 & $127.2(\mathrm{CH})$ & $126.0(\mathrm{CH})$ & $127.4(\mathrm{CH})$ & $127.4(\mathrm{CH})$ \\
\hline 15 & $119.2(\mathrm{C})$ & $119.3(\mathrm{C})$ & $119.4(\mathrm{C})$ & $119.4(\mathrm{C})$ \\
\hline 16 & $20.6\left(\mathrm{CH}_{2}\right)$ & $20.0\left(\mathrm{CH}_{2}\right)$ & $20.7\left(\mathrm{CH}_{2}\right)$ & $20.7\left(\mathrm{CH}_{2}\right)$ \\
\hline 17 & $52.8\left(\mathrm{CH}_{2}\right)$ & $50.2\left(\mathrm{CH}_{2}\right)$ & $52.9\left(\mathrm{CH}_{2}\right)$ & $52.9\left(\mathrm{CH}_{2}\right)$ \\
\hline 19 & $150.3(\mathrm{C})$ & $150.2(\mathrm{C})$ & $150.4(\mathrm{C})$ & $150.4(\mathrm{C})$ \\
\hline 20 & $101.8(\mathrm{C})$ & $100.4(\mathrm{C})$ & $100.6(\mathrm{C})$ & $100.6(\mathrm{C})$ \\
\hline 21 & $122.7(\mathrm{C})$ & $122.2(\mathrm{C})$ & $122.7(\mathrm{C})$ & $122.7(\mathrm{C})$ \\
\hline $1^{\prime}$ & - & & $171.0(\mathrm{C})$ & $173.6(\mathrm{C})$ \\
\hline $2^{\prime}$ & - & & $20.4\left(\mathrm{CH}_{3}\right)$ & $34.0\left(\mathrm{CH}_{2}\right)$ \\
\hline $3^{\prime}$ & - & & - & $25.8\left(\mathrm{CH}_{2}\right)$ \\
\hline $4^{\prime}$ & - & & - & $27.5\left(\mathrm{CH}_{2}\right)$ \\
\hline $5^{\prime}$ & - & & - & $129.7(\mathrm{CH})$ \\
\hline $6^{\prime}$ & - & & - & $131.7(\mathrm{CH})$ \\
\hline $7^{\prime}$ & - & & - & $28.4\left(\mathrm{CH}_{2}\right)$ \\
\hline $8^{\prime}$ & - & & - & $28.4\left(\mathrm{CH}_{2}\right)$ \\
\hline $9^{\prime}$ & - & & - & $130.1(\mathrm{CH})$ \\
\hline $10^{\prime}$ & - & & - & $130.8(\mathrm{CH})$ \\
\hline $11^{\prime}-25^{\prime}$ & - & & - & $\begin{array}{c}28.1-30.9 \\
\left(\mathrm{CH}_{2}\right) ; \\
130.9(\mathrm{CH}) \\
131.4(\mathrm{CH})\end{array}$ \\
\hline $26^{\prime}$ & - & & - & $32.9\left(\mathrm{CH}_{2}\right)$ \\
\hline $27^{\prime}$ & - & & - & $23.7\left(\mathrm{CH}_{2}\right)$ \\
\hline $28^{\prime}$ & - & & - & $14.5\left(\mathrm{CH}_{3}\right)$ \\
\hline
\end{tabular}

${ }^{\mathrm{a}}$ Extracted from HSQC and HMBC spectra.

Compound 4 is a configurationally rigid molecule with seven rings and three stereocenters at $\mathrm{C}-2, \mathrm{C}-6$, and C-8. The relative configurations of these stereogenic centers were proposed by the NOE correlations as shown in Figure 4B. The specific rotation value of $4\left([\alpha]^{20}{ }_{D}=-246, c 0.05\right.$, $\mathrm{MeOH})$ is opposite to that of $(+)-(2 S, 6 R, 8 S)$-discorhabdin $\mathrm{D}\left([\alpha]^{20}{ }_{\mathrm{D}}=+80, c 0.025, \mathrm{MeOH}\right)[26]$. The experimental ECD spectrum of compound 4 (Supplementary Figure S8) showed the same cotton effects as compound $\mathbf{1}(-)-(1 R, 2 S, 6 R, 8 S)$-discorhabdin L. So it is reasonable to assume that compound 4 is $(-)-(2 R, 6 R, 8 S)-2$-bromodiscorhabdin D. 


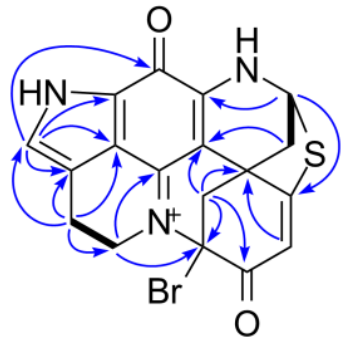

A

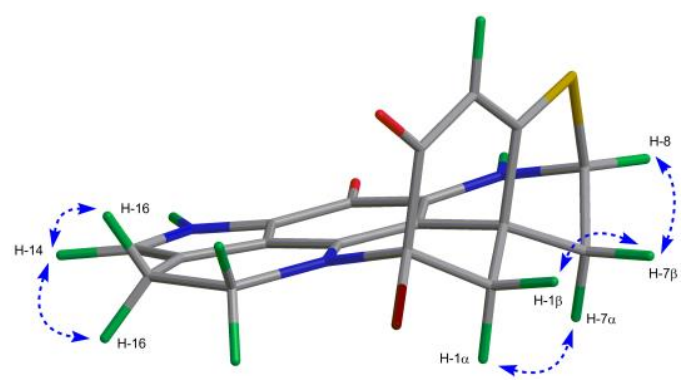

B

Figure 4. Key 2D NMR correlations observed for compound 4. (A) The COSY (in bold), key H $\rightarrow C$ $\mathrm{HMBC}$ (arrows); (B) key $\mathrm{H} \rightarrow \mathrm{H}$ NOESY correlations (dashed line).

Compound 5 was obtained as a green film. Its molecular formula $\mathrm{C}_{20} \mathrm{H}_{16} \mathrm{~N}_{3} \mathrm{O}_{4} \mathrm{~S}$ was deduced by HR-ESIMS $\left(m / z\right.$ 394.0816, $\left.[\mathrm{M}+\mathrm{H}]^{+}\right)$indicating 15 degrees of unsaturation. The FT-IR spectrum of compound 5 displayed the characteristic ester carbonyl absorption band at $v_{\max } 1747 \mathrm{~cm}^{-1}$ and other similar bands as compound (1) at $v_{\max } 1653,1621,1560,1528,1412$, and $1201 \mathrm{~cm}^{-1}$. The ${ }^{1} \mathrm{H}$ and ${ }^{13} \mathrm{C}$ NMR spectra of $\mathbf{5}$ (Tables 2 and 3 ) revealed high similarity with $\mathbf{1}$, with the only difference being the presence of an extra acetyl group in $5\left(\delta_{\mathrm{H}} 2.15 ; \delta_{\mathrm{C}} 171.0\right.$ and $\left.\delta_{\mathrm{C}} 20.4\right)$. The site of esterification was identified as $\mathrm{C}-1$, based on strong $\mathrm{HMBC}$ correlations between $\mathrm{H}-1 / \mathrm{C}-\mathrm{1}^{\prime}$ and a weaker HMBC coupling between $\mathrm{H}-2^{\prime} / \mathrm{C}-1$ (Figure $5 \mathrm{~A}$ ). Thus, the planar structure of compound $\mathbf{5}$ was confirmed as 1-acetyl-discorhabdin L. The analysis of the full 2D NMR dataset (COSY, HSQC, and HMBC) further confirmed that the planar structure of compound 5 (Figure 5A). The relative configuration of compound 5 was elucidated by examining its NOESY spectrum (Figure 5B). The COSY correlation between $\mathrm{H}-4 / \mathrm{H}-7$ (Supplementary Figure S32) indicated a planar " $W$ " arrangement [28] of the molecule as observed in discorhabdins L [13] and $\mathrm{D}$ [23], thus allowing the assignment of the resonance at $\delta_{\mathrm{H}} 2.63$ to $\mathrm{H}-7 \alpha$ [13]. The stereochemistry at C-1 was proposed by the strong NOE correlation (Figure $5 \mathrm{~B}$ ) between $\mathrm{H}-1 / \mathrm{H}-7 \alpha$. To establish the absolute configuration of (-)-5, its experimental ECD spectrum was compared with that of (-)-(1R,2S,6R,8S)-discorhabdin L (1) (Supplementary Figure S8). The same Cotton effects observed at 290, 360, and $440 \mathrm{~nm}$ for both compounds established the absolute configuration of 5 as $1 R, 2 S, 6 R, 8 S$. Finally, the comparison of the specific rotation values of compounds $\mathbf{1}\left([\alpha]^{20} \mathrm{D}=-71, c 0.1, \mathrm{MeOH}\right)$ and $\mathbf{5}$ $\left([\alpha]^{20}{ }_{\mathrm{D}}=-420, c 0.01, \mathrm{MeOH}\right)$ identified the structure of 5 as $(-)-(1 R, 2 S, 6 R, 8 S)-1$-acetyl-discorhabdin $\mathrm{L}$.

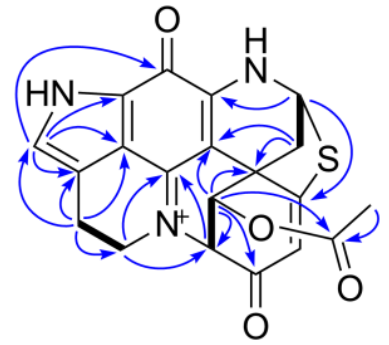

(A)

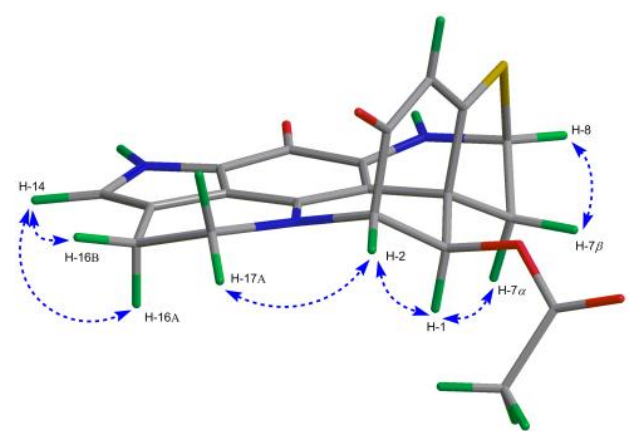

(B)

Figure 5. Key 2D NMR correlations observed for compound 5. (A) The COSY (in bold), key H $\rightarrow$ C $\mathrm{HMBC}$ (arrows); (B) key $\mathrm{H} \rightarrow \mathrm{H}$ NOESY correlations (dashed line).

The most nonpolar component, compound 6, was obtained as a green film with an $[\alpha]^{20}$ value of $+541(c 0.1, \mathrm{MeOH})$. It showed a molecular ion peak at $m / z 752.4452[\mathrm{M}+\mathrm{H}]^{+}$in the HR-ESIMS spectrum. The molecular formula of $\mathrm{C}_{46} \mathrm{H}_{62} \mathrm{~N}_{3} \mathrm{O}_{4} \mathrm{~S}$ was deduced from its ${ }^{13} \mathrm{C}$ NMR and HR-ESIMS data (Table 3 and Supplementary Figure S41), indicating 18 degrees of unsaturation. The FT-IR spectrum contained absorption bands typical of an ester function $\left(v_{\max } 1739 \mathrm{~cm}^{-1}\right)$ and an alkyl chain $\left(v_{\max } 2927\right.$ 
and $2855 \mathrm{~cm}^{-1},-\mathrm{CH}_{2}$ and $-\mathrm{CH}_{3}$ stretching bands). Comparison of the 1D-NMR data of 6 with those of 1 and 5 (Tables 2 and 3) suggested $\mathbf{6}$ to be another analog of discorhabdin L esterified with a long chain fatty acid $\left(\delta_{\mathrm{C}} 25-35 \mathrm{ppm} ; \delta_{\mathrm{H}} 1.2-1.4 \mathrm{ppm}\right)$, which made this molecule very lipophilic. The discorhabdin L core structure that was evident from the 1D and 2D NMR data of 6 (Tables 2 and 3; Figure 6) accounted for 14 degrees of unsaturation. The additional ester carbonyl at $\delta_{C} 173.6$ and six sp ${ }^{2}$ carbons belonging to three double bonds at $\delta_{C}$ 129.7, 130.1, 130.8, 130.9, 131.4, and 131.7 (Supplementary Figure S36) accounted for the remaining 4 degrees of unsaturation. Hence, we concluded that the alkyl chain was an unbranched octacosa-triene-oic acid (28:3) (Tables 2 and 3). The HMBC correlation between $\mathrm{H}-1\left(\delta_{\mathrm{H}}\right.$ $5.79)$ and $C-1^{\prime}\left(\delta_{C} 173.6\right)$ supported the attachment of the fatty acid at C-1 (Figure $\left.6 \mathrm{~A}\right)$. The geometry of these three double bonds in the fatty acid portion was elucidated by analyzing the ${ }^{13} \mathrm{C}$ NMR chemical shifts of the six carbons neighboring the double bonds [29]. Carbon atoms adjacent to cis double bonds resonate around $\delta_{C} 26.0-28.5$, whereas those adjacent to trans double bonds appear at higher chemical shift values, namely $\delta_{C} 29.5-38.0$ [29]. The observed ${ }^{13} \mathrm{C}$ NMR shifts in $(+)-6$ at $\delta_{C} 27.5,28.1,28.2(\times 2)$, $28.4(\times 2)$ confirmed the $\operatorname{cis}(Z)$ configuration of all three double bonds in the fatty acid part (Table 3$)$. The COSY correlations from $C-2^{\prime}$ to $C-10^{\prime}$ and $\mathrm{HMBC}$ correlations between $\mathrm{H}_{2}-2^{\prime} / \mathrm{C}-1^{\prime}, \mathrm{C}-4^{\prime} ; \mathrm{H}_{2}-3^{\prime} / \mathrm{C}-1^{\prime}$, C- $4^{\prime}, \mathrm{C}-5^{\prime} ; \mathrm{H}-6^{\prime} / \mathrm{C}-4^{\prime}, \mathrm{C}-7^{\prime}, \mathrm{C}-8^{\prime} ; \mathrm{H}_{2}-7^{\prime} / \mathrm{C}-9^{\prime}$ (Figure $6 \mathrm{~A}$ ) allowed us to corroborate the position of two unsaturations at $C-5^{\prime}$ and $C-9^{\prime}$, and to assign the $C-1^{\prime}$ to $C-10^{\prime}$ portion of the fatty acid (Figure 3). Comparison of the 1D NMR data of (+)-6 with the literature [30] also supports the presence of a $\Delta^{5,9}$ unsaturated fatty acid. This finding is not surprising since these cis,cis-5,9-dienoic lipids are common in sponges [31]. The chemical shift values of C-26', C-27' and C-28' (Table 3) were also assigned by comparison with the literature data [32]. Thus, compound (+)-6 was identified as C-1 octacosatrienoic acid (C28:3) ester of (-)-discorhabdin L (Figure 3). Due to availability of very minor amount of the compound $(0.2 \mathrm{mg})$ and the failed attempts to improve the highly overlapped NMR signals through different solvents (e.g., $\mathrm{MeOD}, \mathrm{CDCl}_{3}$, and DMSO-d6), we were unable to confirm the position of the third double bond. However, we believe that the lipid residue in $\mathbf{6}$ is related to the well-known 5Z,9Z demospongic acids bearing another double bond at C-17, or C-19, or C-23 [31].

On the basis of a strong NOE correlation between $\mathrm{H}-1$ and $\mathrm{H}-7 \alpha$ (Figure $6 \mathrm{~B}$ ), as well as the other NOE correlations shown in Figure 6B, the relative configuration of 6 was elucidated to be the same as compounds 1 and 5. The absolute configuration of 6 was established by comparing its experimental ECD spectrum with those of 1 and $\mathbf{5}$ (Supplementary Figure S8). Based on the opposite sign of the specific rotation value of $6\left([\alpha]^{20} \mathrm{D}=+541, c 0.1, \mathrm{MeOH}\right)$ in comparison to compounds $1\left([\alpha]^{20}{ }_{\mathrm{D}}=-71, c 0.1, \mathrm{MeOH}\right)$ and $5\left([\alpha]^{20} \mathrm{D}=-420, c 0.01, \mathrm{MeOH}\right), 6$ was identified as (+)-(1R,2S,6R,8S)-1-octacosatrienoyl-discorhabdin L (Figure 3).

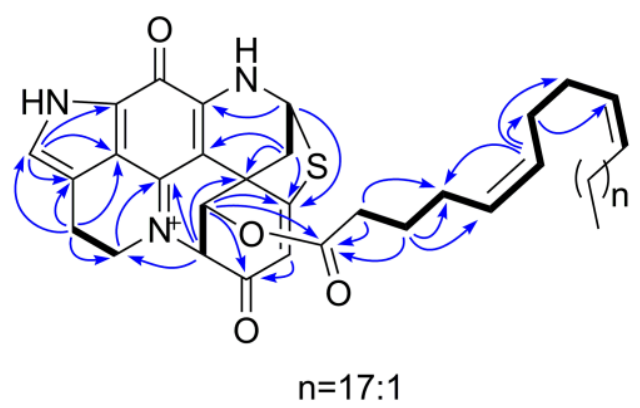

(A)

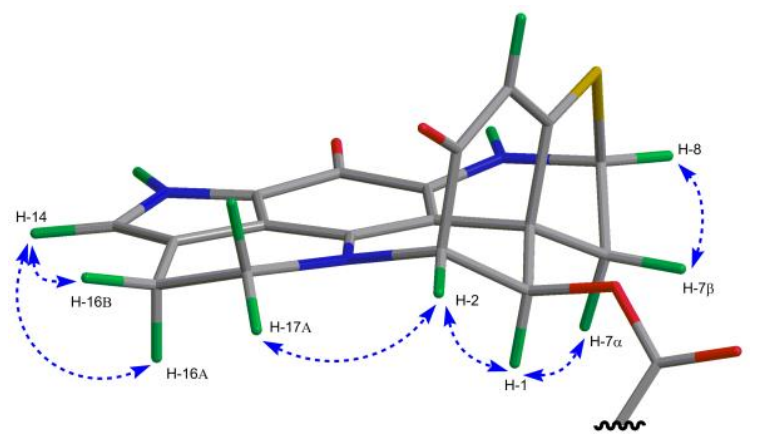

(B)

Figure 6. Key 2D NMR correlations observed for compound 6. (A) The COSY (in bold), key $\mathrm{H} \rightarrow \mathrm{C}$ $\mathrm{HMBC}$ (arrows); (B) key $\mathrm{H} \rightarrow \mathrm{H}$ NOESY correlations (dashed line).

\subsection{In Vitro Bioactivity Tests and Molecular Docking on Purified Compounds}

Anticancer activity of the pyrroloiminoquinone-type alkaloids has been the main driving force for isolation of these intriguing structural types. Due to low quantities of the isolated compounds, 
we were only able to assess the in vitro anticancer activities of compounds 1, 5, and $\mathbf{6}$ against one cell line. We used HCT-116 colon cancer cells for testing, because of the observed high activity of the $\mathrm{MeOH}$ subextract and SPE fractions (Table 1), plus the availability of literature data for (-)-discorhabdin L (1) against this cell line $\left(\mathrm{IC}_{50}\right.$ value $\left.6.2 \mu \mathrm{M}\right)$ [17]. In the current study, compound 1 showed $\mathrm{IC}_{50}$ value of $0.94 \mu \mathrm{M}$ (equal to $0.33 \mu \mathrm{g} / \mathrm{mL}$ ). The compound 5 displayed promising activity with an $\mathrm{IC}_{50}$ value of $2.71 \mu \mathrm{M}(=1.1 \mu \mathrm{g} / \mathrm{mL})$, while compound 6 was only modestly active against the same cell line $\left(\mathrm{IC}_{50}\right.$ value $34.0 \mu \mathrm{M}$, equal to $25.6 \mu \mathrm{g} / \mathrm{mL}$ ). These results indicate that $\mathrm{C}-1 \mathrm{OH}$ function is important for anti-colon cancer activity and the substitution of the $\mathrm{C}-1 \mathrm{OH}$ group, especially with a long chain fatty acyl function is not favored.

Limited by the amounts of the isolated compounds, we performed a molecular modeling study (using Schrödinger software Maestro; www.schrodinger.com) on compounds 1-6 and (+)-discorhabdin $\mathrm{L}(\mathbf{1 e})$, the (+) enantiomer of compound 1, against two known anticancer targets (topoisomerase I/II, indoleamine 2,3-dioxygenase IDO1) to estimate their potential anticancer activity and mechanism(s) of action. Where possible, based on suitable pdb structures, docking experiments were performed. We prepared available relevant pdb protein structures, removed the original ligands, and generated receptor grids. Small molecule 3D structures of the compounds containing a quaternary nitrogen were energetically minimized and possible tautomers/protonated states were evaluated (LigPrep, counter ion not specified). Next, we docked the optimized ligand structures into respective active sites (Glide $\mathrm{SP})$. Calculated 3D binding modes were illustrated, or presented as 2D ligand-interaction diagrams, for clarity.

Docking of compounds 1-5 into the active site of topoisomerase I (pdb 1T8I) yielded plausible binding modes (Figure 7), while no binding pose could be calculated for compound 6, due to the sterically demanding side chain that did not fit into the tight binding pocket). Compared to the original ligand camptothecin, the flat, partly aromatic core of the discorhabdins 1-5 intercalated into the DNA part thereby forming aromatic $\pi$ - $\pi$-stacking interactions while also addressing H-bonds towards residues of the topoisomerase I protein. Similar results were obtained by docking experiments with topoisomerase II (pdb 3QX3, original ligand etoposide) suggesting these proteins to be anticancer targets for the compounds 1-5. Molecular docking study performed (in analogy to the procedure described above) on compound 1e, which was reported to exhibit strong in vitro cytotoxicity [33], revealed a binding mode in the active site of topoisomerase I, too (Figure 7). Comparable to 1, the flat core forms a DNA-intercalating complex, but the ligand is distorted by $180^{\circ}$. Thus, the binding modes of both compounds, $\mathbf{1}$ and 1e, suggest those ligands to be rather non-specific DNA intercalators.

We also performed docking experiments with another reported target for pyrroloiminoquinone alkaloids, namely the indoleamine 2,3-dioxygenase (IDO1) enzyme for which structural data including ligand-protein complexes are available. As cofactor to mediate physiological substrate oxidation, IDO1 contains a heme moiety and ligands typically form interactions by complexing the iron central atom. Examples for such IDO1 inhibitors and relevant interacting moieties include NLG919 derivative (imidazole-like nitrogen in pdb 5EK2) or ligand INCB14943 (hydroxylamidine moiety in pdb 5XE1). Since the compounds lack comparable nitrogen functionalities to able to interact with heme in a similar manner, docking of the compounds into these active sites revealed no plausible binding modes. However, recent reports demonstrated that another class of potent IDO1 inhibitors such as FXB-001116 (pdb 6AZW) and BMS-978587 (pdb 6AZV) bind to the IDO1 apo structure with high affinity, thereby displacing the heme moiety. Accordingly, we performed docking experiments of compounds 1-6 and 1e using the apo-protein. This approach suggested possible binding modes for compounds 1-4 and 1e in the apo active site of IDO1 (Figure 8), but not for the sterically more demanding compounds 5 and $\mathbf{6}$. 


\section{Compound}

1

$1 e$

2
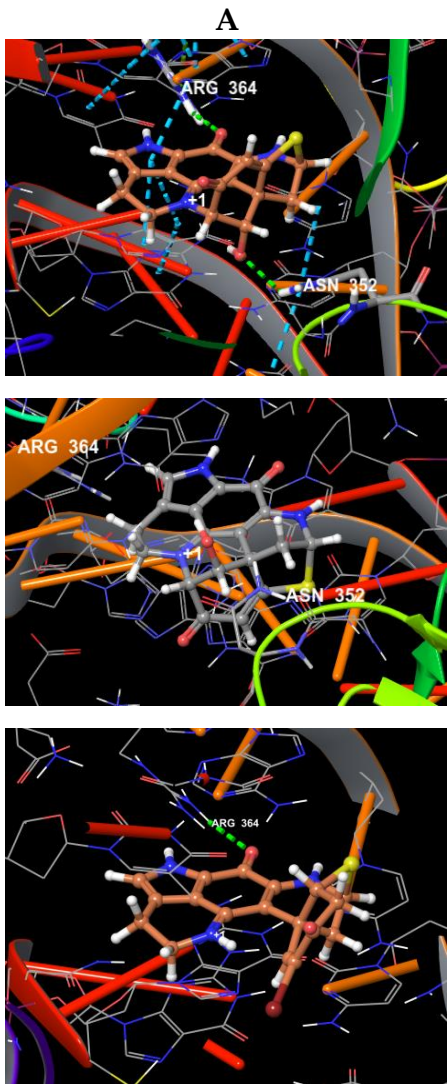

3

4
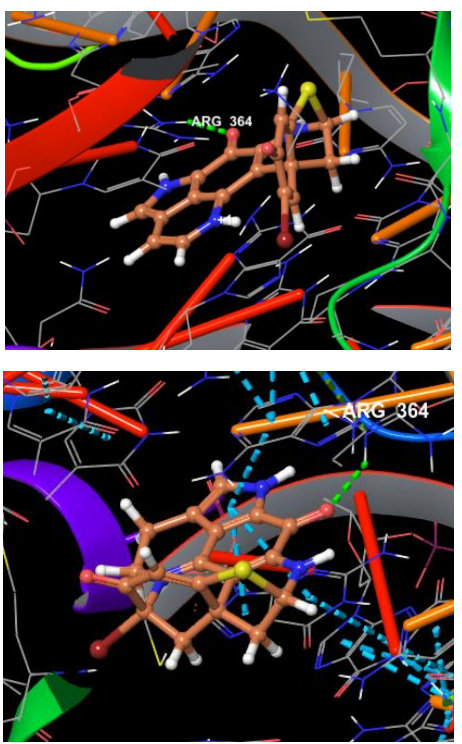

5

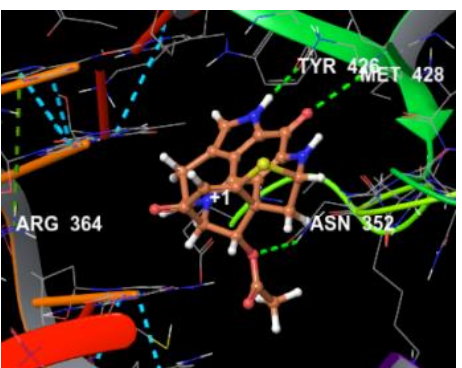

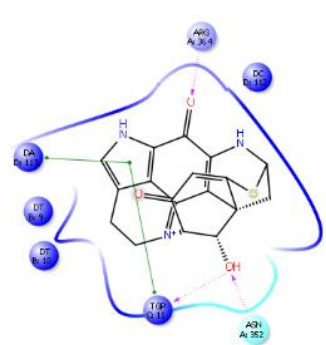
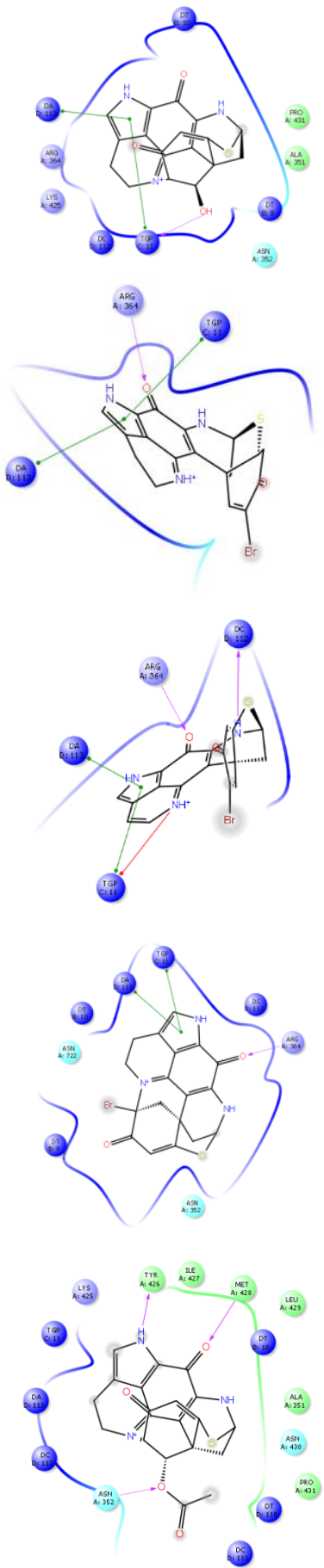

Figure 7. (A) Calculated 3D binding modes of compounds 1-5 and $\mathbf{1 e}$ in the active site of topoisomerase I (pdb 1T8I) also containing a DNA molecule (colored in red) with a single strand break; (B) corresponding 2D ligand interaction diagrams showing key interactions of compounds 1-5 and 1e towards topoisomerase I and DNA. 
Compound

1

1e

2

3
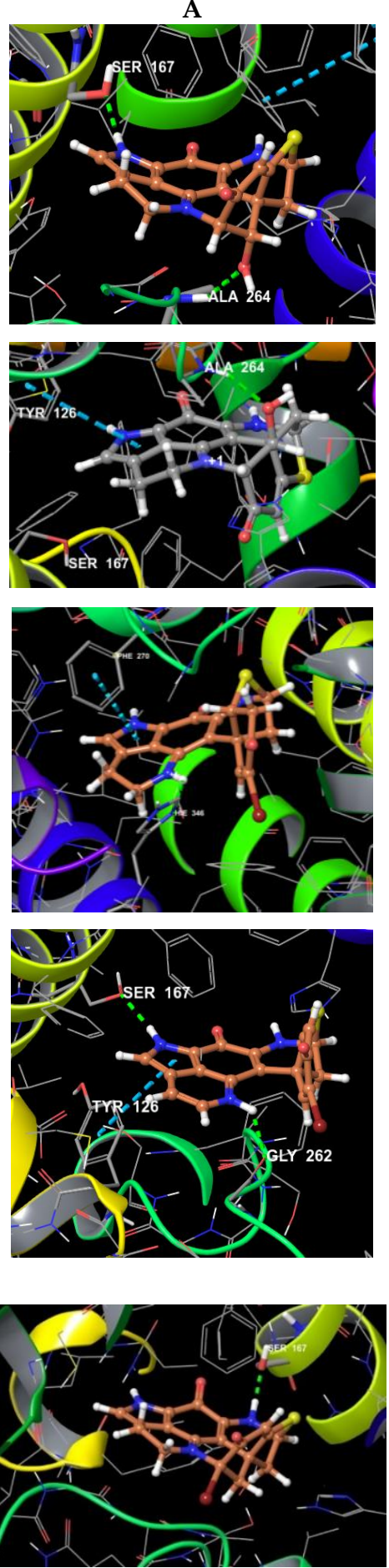
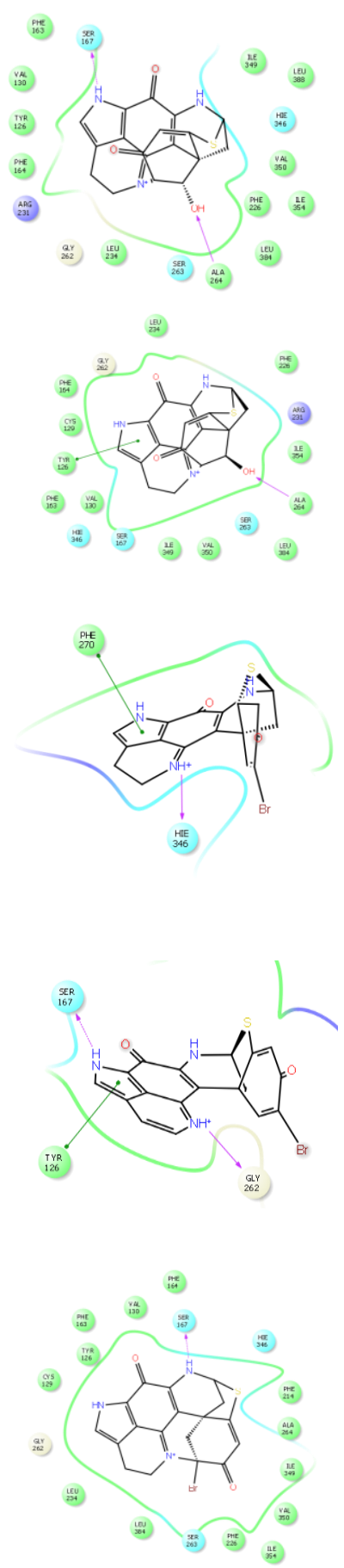

Figure 8. 3D binding poses (A) and ligand interaction diagrams (B) of compounds 1-4 and 1e in the active site of IDO1 (pdb 6AZW). Key interactions are shown. The binding pocket is shown in a similar orientation, respectively. Ligand docking revealed plausible binding poses for compounds 1-4 and 1e, but not for compounds 5 and $\mathbf{6}$.

Inspecting the docking poses of $\mathbf{1}$ in the above-mentioned protein structures on a molecular level pointed towards a key role for the sterically defined $\mathrm{OH}$-function in $\mathbf{1}$, as it mediates an $\mathrm{H}$-bond towards Ala264. Another key H-bond interaction occurred between aromatic NH of $\mathbf{1}$ towards Ser167 (Figure 8). Compound 1 shows a rather planar core, anchoring the ligand with a strong shape-fit into the tight binding pocket. Relative to this core, the thioether bridge sits almost rectangular on top, 
occupying a lipophilic area within the binding site, flanked by residues including Val350, Phe226, and Leu384. Within these small sets of compounds, docking of $\mathbf{1}$ reveals the optimal pose. We also docked (+)-discorhabdin L (1e), the enantiomer of $\mathbf{1}$, into the active site of IDO1 (in analogy to the procedure described above). Interestingly, the flat core was found to again fill the rather flat pocket. In comparison to 1, the core sits upside down in 1e, with the key H-bond towards Ala264 being maintained. Accordingly, the NH-bond towards Ser167 was lost, but the aromatic system formed a $\pi$-interaction to Tyr126 (Figure 8). These poses suggest the flat aromatic core of this type of compounds to be the main requisite to bind into the pocket. Furthermore, stereochemistry seems to play a minor role in binding. Thus, it can be assumed the compounds are rather non-specific IDO1-ligands.

The calculated binding mode of compound 4 yielded a shifted orientation of the core, with only one H-bond towards Ser167 (Figure 8). In contrast, compounds 5 and $\mathbf{6}$ gave no plausible docking solutions, again due to the sterically demanding ester moieties, thus also preventing H-bonding by $\mathrm{OH}$ towards Ala264.

In summary, the molecular modeling data suggested plausible binding modes for compounds 1-5 in the target structure of topoisomerase I, and for compounds 1-4 towards IDO1, respectively. However, it is well possible that this class of compounds bind further key anticancer targets, contributing to their cytotoxic potential.

\section{Discussion}

Since the discovery of discorhabdin C from a New Zealand Latrunculia sp. in 1986 [8], more than 40 discorhabdin analogs have been reported from different marine sponge genera [34]. Some discorhabdins contain bromination at C-2, C-4, or C-14 positions (e.g., discorhabdin A, discorhabdin C, 14-bromodihydrodiscorhabdin C) $[8,23,24,35]$, some possess a sulfur bridge between C-5 and C-8 (e.g., discorhabdin B, discorhabdin Q) [24,36]. A few discorhabdins (e.g., discorhabdin L, discorhabdin D) are heptacyclic through the formation of an extra bridge between C-2 and N-18 [13,24]. Of the six compounds obtained in the current study, two of them (5 and $\mathbf{6})$ are (-)-discorhabdin L esters. Compound 6 is a triunsaturated C28 fatty acid ester of discorhabdin L. To our knowledge this is the first discorhabdin alkyl ester structure being reported from a marine sponge. Notably, Zou et al. (2013) reported atkamine, a new, large pyrroloiminoquinone scaffold containing a fused epoxybenzazepin and bromophenol groups connected with a cyclic sulfide ring [37]. Between the former and the latter rings, there is a substitution with a monosaturated C20 alkyl chain. The authors suggested this alkyl group to originate from (Z)-15-docosenoic acid, a fatty acid commonly found in sponge species that was possibly incorporated in the very early biosynthesis stages of atkamine [37]. Compounds 5 and $\mathbf{6}$ isolated in this study instead bear an esterification at C-1 position of the pyrroloiminoquinone ring system. Compound 5 is an acetyl ester of (-)-discorhabdin L, while $\mathbf{6}$ is an ester of discorhabdin L with an unbranched octacosatrienoic acid. Marine sponges, especially demosponges, are regarded as one of the richest sources of long-chain fatty acids (LCFAs; i.e., C23-34) [38,39]. The octacosatrienoic acid (C28:3) has been reported from marine sponges and corals [40-42], but not from any Latrunculia species. The only study that analyzed the FAs composition of Antarctic Latrunculia sponges in 2015 showed that Antarctic L. biformis contained diverse common and LCFAs (C16, C18), however longer chain unsaturated FAs were not found [43]. This is the first report of a discorhabdin-LCFA ester from nature, and the current study adds three new and intriguing analogs to the list of discorhabdin class alkaloids.

Discorhabdins have been repeatedly studied for their in vitro anticancer activity $[10,13,14]$. Limited by the strong cytotoxicity and the supply issue, no molecule from this chemical family has ever proceeded to further clinical studies. A few structure-activity relationship studies (SARs) associated with discorhabdins have been conducted, revealing that the ring closure by a bridge between $\mathrm{C} 2$ and N18 can significantly reduce the cytotoxicity, while a substitution at C-1 (i.e., $\mathrm{OMe}, \mathrm{NH}_{2}$ ) can enhance the anticancer activity $[19,26]$. The discovery of C-1 esters of discorhabdin L with good to moderate inhibitory activity against HCT-116 cell line here provides further insights for the SARs of discorhabdins. 
Although many discorhabdins are associated with anticancer/cytotoxic activity, little is known on their exact mechanism(s) of action. Wada et al. (2011) evaluated (+)-discorhabdin A and its synthetic oxa analog for inhibition against a set of anticancer target enzymes, such as protein kinase, histone deacetylase, farnesyltransferase, telomerase, and proteasome [16]. (+)-Discorhabdin A and its synthetic oxa analog weakly inhibited the farnesyltransferase enzyme $\left(\mathrm{IC}_{50}>10 \mu \mathrm{M}\right)$ [16]. Geoy et al. recently tested the HIF- $1 \alpha /$ p300 inhibition activity of several discorhabdins, including (-)-discorhabdin $\mathrm{L}\left(\mathrm{IC}_{50}\right.$ value $0.73 \mu \mathrm{M}$ ) concluding them to be a novel class of HIF-1 $\alpha / \mathrm{p} 300$ inhibitors [17]. In the current study, an in silico molecular modeling study revealed the plausible binding modes of discorhabdins in two additional cancer target enzymes, topoisomerase I/II and IDO1.

In summary, guided by the anticancer activity and MN-based metabolomics, the Antarctic deep-sea sponge L. biformis led to the isolation and characterization of three known and three new discorhabdin alkaloids. Despite the small amounts of the extract and fractions that hampered the isolation of many further new discorhabdins, MN-based metabolomics proved useful for identification of chemical inventory of the sponge in early stages. Two compounds were a new type of discorhabdin esters that yielded meaningful SARs in comparison to the parent compound discorhabdin L. Mechanistic studies based on molecular modeling showed, for the first time, the potential binding of discorhabdins to additional anticancer targets that may be involved in their anticancer activity.

\section{Materials and Methods}

\subsection{General Procedures}

Specific rotation of compounds 1-6 were measured on a Jasco P-2000 polarimeter (Jasco, Pfungstadt, Germany). FT-IR spectra were recorded using a PerkinElmer Spectrum Two FT-IR spectrometer (PerkinElmer, Boston, MA, USA). UV spectra were run on a NanoVue Plus spectrophotometer (GE Healthcare, New York, NY. USA). ECD spectra were run in MeOH on a J-810 CD spectrometer (Jasco, Pfungstadt, Germany). NMR spectra were obtained on a Bruker AV 600 spectrometer (600 and $150 \mathrm{MHz}$ for ${ }^{1} \mathrm{H}$ and ${ }^{13} \mathrm{C}$ NMR, respectively, Bruker ${ }^{\circledR}$, Billerica, MA, USA) equipped with $5.0 \mathrm{~mm}$ Shigemi tube (SHIGEMI, Co., LTD., Tokyo, Japan). The residual solvent signals were used as internal references: $\delta_{\mathrm{H}}$ $3.31 / \delta_{\mathrm{C}} 49.0 \mathrm{ppm}(\mathrm{MeOD})$, and $\delta_{\mathrm{H}} 2.50 / \delta_{\mathrm{C}} 39.51 \mathrm{ppm}\left(\mathrm{DMSO}-d_{6}\right)$. 4-Dimethyl-4-silapentane-1-sulfonic acid (DSS) served as the internal standard. HRMS/MS data were recorded on a Waters Xevo G2-XS QTof Mass Spectrometer (Waters ${ }^{\circledR}$, Milford, MA, USA) coupled to a Waters Acquity I-Class UPLC system (Waters ${ }^{\circledR}$, Milford, MA, USA). HR-ESIMS was recorded on micrOTOF II-High-performance TOF-MS system (Bruker ${ }^{\circledR}$, Billerica, MA, USA) equipped with an electrospray ionization source. Solid phase extraction (SPE) was performed on the Chromabond SPE C18 column cartridges $(6 \mathrm{~mL} / 2000 \mathrm{mg}$, Macherey-Nagel, Duren, Germany). HPLC separations were performed on a VWR Hitachi Chromaster system (VWR International, Allison Park, PA, USA) consisting of a 5430-diode array detector (VWR International, Allison Park, PA, USA), a 5310-column oven, a 5260 autosampler, and a 5110 pump combined in parallel with a VWR evaporative light scattering detector (ELSD 90, VWR International, Allison Park, PA, USA). The eluents used for HPLC separations were $\mathrm{H}_{2} \mathrm{O}(\mathrm{A})$ and $\mathrm{MeCN}$ (B). Routine HPLC separations were performed on a semi-preparative C18 monolithic column (Onyx, $100 \times 10 \mathrm{~mm}$, Phenomenex, Torrance, CA, USA) and an analytical synergi column $(250 \times 4.6 \mathrm{~mm}$, Phenomenex, Torrance, CA, USA). A chiral cellulose- 1 column (Lux $5 \mu, 250 \times 4.6 \mathrm{~mm}$, Phenomenex, Torrance, CA, USA) was used for checking the enantiopurity of each purified compound. The organic solvents used for UPLC-QToF-MS/MS analyses were ULC/MS grade (Biosolve BV, North Brabant, Netherlands) and HPLC grade (ITW Reagents, Darmstadt, Germany) for HPLC isolation processes. The water used was MilliQ-water produced by Arium ${ }^{\circledR}$ Water Purification Systems (Sartorius, Göttingen, Germany).

\subsection{Sponge Material}

The sponge was collected in 2015/2016 during the Expedition PS96 of the Research Vessel POLARSTERN to the southern Weddell Sea (Antarctica). The sponge was collected by an Agassiz 
trawl at a depth of $-291 \mathrm{~m}$, and was fixated immediately after collection. Specimens were cleaned, pre-sorted, photographed, and transferred into buckets with cold seawater as soon as the catch was on deck. Subsamples were transferred into pure ethanol (96\%) and the main parts were frozen at $-20^{\circ} \mathrm{C}$. The sponges were transported to the Senckenberg Research Institute and Nature Museum in Frankfurt am Main, Germany. Tissue samples were taken and skeletal preparations were made for transmission light microscopy and SEM, according to standard protocols [44]. For taxonomic examination, the sponge spicules were mounted on microscope slides and studied by light microscopy and by SEM. Based on comparative morphology of skeletal characters, the sponge was identified as Latrunculia biformis, which is a common species in the Antarctic deeper shelf areas. For identification, the World Porifera Database [45] and relevant literature were used. A specimen (SMF 12109) is deposited in the Porifera collection of Senckenberg Research Institute and Nature Museum, electronically inventoried. The data are online available in the SESAM database.

\subsection{Extraction and Isolation}

The sponge material (43.615 g, frozen weight) was cut into small pieces and freeze-dried (Martin Christ, Osterode am Harz, Germany). The lyophilized biomass (5.809 g) was extracted at room temperature with water $(3 \times 200 \mathrm{~mL})$ under agitation to yield the aqueous extract $(1.892 \mathrm{~g})$. The remaining sponge residue $(3.572 \mathrm{~g}$, dry weight) was extracted with $\mathrm{MeOH}(3 \times 150 \mathrm{~mL})$ and subsequently with DCM $(3 \times 150 \mathrm{~mL})$ under the same conditions. Combined $\mathrm{MeOH}$ and DCM extracts were evaporated to dryness by a rotary evaporator to yield the crude organic extract $(328 \mathrm{mg})$ that showed very strong anticancer activity against multiple cancer cell lines. This extract was partitioned between $\mathrm{MeOH}(100 \mathrm{~mL})$ and $n$-hexane $(100 \mathrm{~mL})$ to yield $\mathrm{MeOH}(190 \mathrm{mg})$ and $n$-hexane $(120 \mathrm{mg})$ subextracts. The $\mathrm{MeOH}$-soluble portion, which exhibited strong anticancer activity was fractionated on a Chromabond SPE C18 cartridge. The elution with a step gradient $\mathrm{MeOH}: \mathrm{H}_{2} \mathrm{O}$ mixture $(0 \%$ to $100 \%)$ afforded 8 fractions (M1-M8), of which the anticancer activity was tracked to six fractions M2-M5, M7, and M8. RP-HPLC separation of M2 (18 mg) on the analytical Synergi column gradient of $\mathrm{H}_{2} \mathrm{O}: \mathrm{MeCN}$ (77:22), with $0.1 \%$ TFA, flow $1.0 \mathrm{~mL} / \mathrm{min}$ yielded compound $\mathbf{1}\left(1.5 \mathrm{mg}, t_{\mathrm{R}} 5.5 \mathrm{~min}\right)$. RP-HPLC analysis of M3 (10 mg) on the same column (gradient of $\mathrm{H}_{2} \mathrm{O}: \mathrm{MeCN}$ from 80:20 to 70:30 in $25 \mathrm{~min}$, with $0.1 \%$ TFA, flow $1.0 \mathrm{~mL} / \mathrm{min}$ ) afforded compounds $5\left(0.3 \mathrm{mg}, t_{\mathrm{R}} 15.2 \mathrm{~min}\right)$ and 3 (0.3 mg, $\left.t_{\mathrm{R}} 19.0 \mathrm{~min}\right)$. M4 (16 mg) was further fractionated on a Chromabond SPE C18 cartridge to furnish 5 subfractions (M4-1 to M4-5). The subfraction M4-1 (4.4 mg) was further purified by RP-HPLC equipped with an analytical C18 column using a gradient of $\mathrm{H}_{2} \mathrm{O}: \mathrm{MeCN}(87: 13$ to $80: 20,0-16 \mathrm{~min}, 80: 20$ to $74: 26,16-27 \mathrm{~min}$, with $0.1 \%$ TFA, flow $1.0 \mathrm{~mL} / \mathrm{min})$ to yield compounds $4\left(0.1 \mathrm{mg}, t_{\mathrm{R}} 18.9 \mathrm{~min}\right)$ and $2\left(0.1 \mathrm{mg}, t_{\mathrm{R}} 20.5 \mathrm{~min}\right)$. RP-HPLC separation of the nonpolar fraction M8 (23.9 mg) (gradient of $\mathrm{H}_{2} \mathrm{O}: \mathrm{MeCN} 25: 75$ to 0:100, 0-15 min, with $0.1 \%$ TFA, flow $1.0 \mathrm{~mL} / \mathrm{min}$ ) on an analytical C18 column yielded compound 6 ( $\left.0.2 \mathrm{mg}, t_{\mathrm{R}} 14.9 \mathrm{~min}\right)$. Each purified compound was further checked, individually, for enantiopurity by RP-DAD-HPLC on a chiral analytical column using a gradient of $\mathrm{H}_{2} \mathrm{O}: \mathrm{MeCN}$ (99:1 to 0:100, 0-15 min, with $0.1 \%$ TFA, flow $1.5 \mathrm{~mL} / \mathrm{min})$.

$(-)-(1 R, 2 S, 6 R, 8 S)-$ Discorhabdin L (1): Greenish film; $[\alpha]^{20}{ }_{\mathrm{D}}=-71($ c $0.1, \mathrm{MeOH}) ;{ }^{1} \mathrm{H} \mathrm{NMR}\left(\mathrm{CD}_{3} \mathrm{OD}\right.$, $600 \mathrm{MHz})$ and ${ }^{13} \mathrm{C}$ NMR $\left(\mathrm{CD}_{3} \mathrm{OD}, 150 \mathrm{MHz}\right)$ Tables 2 and 3; HR-ESIMS found $m / z[\mathrm{M}+\mathrm{H}]^{+} 352.0748$, $\mathrm{C}_{18} \mathrm{H}_{14} \mathrm{~N}_{3} \mathrm{O}_{3} \mathrm{~S}$ requires 352.0756 .

(+)-(5R,6S,8S)-Discorhabdin A (2): Orange film; $[\alpha]^{20} \mathrm{D}=+197$ (c 0.01, MeOH); HR-ESIMS found $m / z$ $[\mathrm{M}+\mathrm{H}]^{+} 416.0065, \mathrm{C}_{18} \mathrm{H}_{15}{ }^{79} \mathrm{BrN}_{3} \mathrm{O}_{2} \mathrm{~S}$ requires 416.0068 .

(+)-(6S,8S)-Discorhabdin $Q$ (3): Orange film; $[\alpha]^{20}{ }_{\mathrm{D}}=+568(c 0.1, \mathrm{MeOH}) ; \mathrm{HR}-\mathrm{ESIMS}$ found $m / z[\mathrm{M}+\mathrm{H}]^{+}$ 411.9733, $\mathrm{C}_{18} \mathrm{H}_{11}{ }^{79} \mathrm{BrN}_{3} \mathrm{O}_{2} \mathrm{~S}$ requires 411.9759.

(-)-(2R,6R,8S)-2-Bromodiscorhabdin D (4): Greenish film; UV (MeOH) $\lambda_{\max } 250$ (є 13840), 285 (є 11184), 325 (є 7947), 403 (є 7802) nm; $[\alpha]^{20} \mathrm{D}=-246$ (c 0.05, MeOH); IR (film) $v_{\max } 2922,2852,1657,1533$, 
1514, 1432, $1230 \mathrm{~cm}^{-1} ;{ }^{1} \mathrm{H}$ NMR ( $\left.\mathrm{CD}_{3} \mathrm{OD}, 600 \mathrm{MHz}\right)$ and ${ }^{13} \mathrm{C}$ NMR $\left(\mathrm{CD}_{3} \mathrm{OD} 150 \mathrm{MHz}\right)$ Tables 2 and 3; HR-ESIMS found $m / z[\mathrm{M}+\mathrm{H}]^{+} 413.9913, \mathrm{C}_{18} \mathrm{H}_{13}{ }^{79} \mathrm{BrN}_{3} \mathrm{O}_{2} \mathrm{~S}$ requires 413.9912 .

(-)-(1R,2S,6R,8S)-1-Acetyl-discorhabdin L (5): Greenish film; UV (MeOH) $\lambda_{\max } 250$ (є 24822), 283 (є 17019), 325 (є 11700), 403 (є 11169) nm; $[\alpha]^{20}{ }_{D}=-420$ (c 0.01, MeOH); IR (film) $v_{\max } 2926,2854,1747,1653$, 1621, 1560, 1528, 1412, $1201 \mathrm{~cm}^{-1} ;{ }^{1} \mathrm{H}$ NMR ( $\left.\mathrm{CD}_{3} \mathrm{OD}, 600 \mathrm{MHz}\right)$ and ${ }^{13} \mathrm{C} \mathrm{NMR}\left(\mathrm{CD}_{3} \mathrm{OD}, 150 \mathrm{MHz}\right)$ Tables 2 and 3; HR-ESIMS found $m / z[\mathrm{M}+\mathrm{H}]^{+} 394.0816, \mathrm{C}_{20} \mathrm{H}_{16} \mathrm{~N}_{3} \mathrm{O}_{4} \mathrm{~S}$ requires 394.0861.

(+)-(1R,2S,6R,8S)-1-Octacosatrienoyl-discorhabdin L (6): Greenish film; UV (MeOH) $\lambda_{\max } 203$ (є 19890), 249 (є 19439), 285 (є 15904), 325 (є 13122), 403 (є 11543) nm; $[\alpha]^{20}{ }_{\mathrm{D}}=+541$ (c 0.1, MeOH); IR (film) $v_{\max } 3007,2927,2855,1739,1678,1621,1566,1527,1441,1206,1185,1135 \mathrm{~cm}^{-1} ;{ }^{1} \mathrm{H}$ NMR $\left(\mathrm{CD}_{3} \mathrm{OD}, 600\right.$ $\mathrm{MHz})$ and ${ }^{13} \mathrm{C}$ NMR $\left(\mathrm{CD}_{3} \mathrm{OD}, 150 \mathrm{MHz}\right)$ Tables 2 and 3; HR-ESIMS found $m / z[\mathrm{M}+\mathrm{H}]^{+} 752.4452$, $\mathrm{C}_{46} \mathrm{H}_{62} \mathrm{~N}_{3} \mathrm{O}_{4} \mathrm{~S}$ requires 752.4461 .

\subsection{UPLC-QToF-MS/MS Analysis}

The six active C18 SPE fractions of the MeOH soluble portion were analyzed on an ACQUITY UPLC I-Class System coupled to the Xevo G2-XS QToF Mass Spectrometer (Waters ${ }^{\circledR}$, Milford, Massachusetts, USA) equipped with an electrospray ionization (ESI) source operating with a positive polarity at a mass range of $m / z 50-1600 \mathrm{Da}$. The $0.1 \mathrm{mg} / \mathrm{mL} \mathrm{MeOH}$ solution of the fractions were filtered through a $0.2 \mu \mathrm{m}$ PTFE syringe filter (Carl Roth, Karlsruhe, Germany) and then injected (injection volume: $1.0 \mu \mathrm{L}$ ) into the system equipped with Acquity UPLC HSS T3 column (high-strength silica C18, $1.8 \mu \mathrm{m}$, $100 \times 2.1 \mathrm{~mm}$ I.D., Waters ${ }^{\circledR}$ ) operating at $40{ }^{\circ} \mathrm{C}$. Separation was achieved with a binary LC solvent system controlled by MassLynx ${ }^{\circledR}$ (version 4.1 ) using mobile phase A $99.9 \%$ water/ $0.1 \%$ formic acid (ULC/MS grade) and B 99.9\% ACN/0.1\% formic acid (ULC/MS grade), pumped at a rate of $0.6 \mathrm{~mL} / \mathrm{min}$ with the following gradient: Initial, $1 \%$ B; $0.0-12.0 \mathrm{~min}$ to $100 \% \mathrm{~B} ; 12.0-13.0 \mathrm{~min} 100 \% \mathrm{~B}$, and a column reconditioning phase until $15 \mathrm{~min}$.

ESI conditions were set with the capillary voltage at $0.8 \mathrm{kV}$, sample cone voltage at $40.0 \mathrm{~V}$, source temperature at $150{ }^{\circ} \mathrm{C}$, desolvation temperature at $550{ }^{\circ} \mathrm{C}$, cone gas flow in $50 \mathrm{~L} / \mathrm{h}$, and desolvation gas flow in $1200 \mathrm{~L} / \mathrm{h}$. MS/MS setting was linear collision energy (CE) at $30 \mathrm{eV}$. As a control, solvent (methanol) was injected. MassLynx ${ }^{\circledR}$ (Waters ${ }^{\circledR}, \mathrm{V} 4.1$ ) was used to analyze the achieved MS and $\mathrm{MS}^{2}$ data.

\subsection{Molecular Networking}

The network was created using the UPLC-HRMS/MS data generated from the six active $\mathrm{MeOH}$ subfractions of L. biformis. All raw MS/MS data were converted from files (.raw) to mzXML file format using MSConvert (Version 3.6.10051, Vanderbilt University, Nashville, TN, USA). The converted data files were uploaded to the Global Natural Products Social molecular networking (http://gnps.ucsd.edu) platform using FileZilla (https://filezilla-project.org/) and a molecular network was created using the online workflow at GNPS [22]. The data were filtered by removing all MS/MS peaks within $+/-17 \mathrm{Da}$ of the precursor $m / z$. MS/MS spectra were window filtered by choosing only the top 6 peaks in the $+/-$ 50Da window throughout the spectrum. The data were then clustered with MS-Cluster with a parent mass tolerance of $0.1 \mathrm{Da}$ and an MS/MS fragment ion tolerance of $0.05 \mathrm{Da}$ to create consensus spectra. Further, concensus spectra that contained less than 2 spectra were discarded. A network was then created where edges were filtered to have a cosine score above 0.6 and more than 3 matched peaks. Further edges between two nodes were kept in the network if and only if each of the nodes appeared in each other's respective top 10 most similar nodes. The spectra in the network were then searched against GNPS' spectral libraries. The library spectra were filtered in the same manner as the input data. All matches kept between network spectra and library spectra were required to have a score above 0.7 and at least 6 matched peaks. The output molecular networking data were analyzed and visualized using Cytoscape (ver. 3.61) [46]. 


\subsection{Cytotoxicity Assay}

Crude extract of L. biformis and downstream fractions were tested in vitro at a final concentration of $100 \mu \mathrm{g} / \mathrm{mL}$ against 6 human cancer cell lines, Hep G2 (liver cancer cell line, DSMZ, Braunschweig, Germany), HT29 (colorectal adenocarcinoma cell line, DSMZ, Braunschweig, Germany), A375 (malignant melanoma cell line, CLS, Eppelheim, Germany), HCT116 (colon cancer cell line, DSMZ, Braunschweig, Germany), A549 (lung carcinoma cell line, CLS, Eppelheim, Germany), and MDA-MB231 (human breast cancer line, CLS, Eppelheim, Germany). Cells were supplemented at $37^{\circ} \mathrm{C}$ and $5 \%$ $\mathrm{CO}_{2}$ in RPMI 1640 medium (Life Technologies, Darmstadt, Germany) with $10 \%$ fetal bovine serum, $100 \mathrm{U} / \mathrm{mL}$ penicillin and $100 \mathrm{mg} / \mathrm{mL}$ streptomycin. A stock solution of $20 \mathrm{mg} / \mathrm{mL}$ in DMSO was prepared for each test sample. After $24 \mathrm{~h}$ incubation in 96-well plates, the medium in the cells was replaced by $100 \mu \mathrm{L}$ fresh medium containing the test samples and cells were incubated for another $24 \mathrm{~h}$ at $37^{\circ} \mathrm{C}$. Doxorubicin was used as positive control, while $0.5 \%$ DMSO and growth media served as negative controls. All samples were prepared in duplicates. The assay was performed according to the manufacturer's instructions (Promega, Madison, WI, USA). Cells were incubated for $2 \mathrm{~h}$ at $37^{\circ} \mathrm{C}$ and fluorescence at an excitation wavelength of $560 \mathrm{~nm}$ and emission at $590 \mathrm{~nm}$ was measured. For the determination of $\mathrm{IC}_{50}$ values, a dilution series of the extracts were tested following the same procedure as described before. $\mathrm{IC}_{50}$ values were calculated by using Excel to determine the concentration that shows $50 \%$ inhibition of the viability.

\subsection{Molecular Modeling and Docking}

Molecular modeling was performed on a DELL Precision T3610 four core workstation using Schrödinger Maestro (version 11.3, 2017, Schrödinger, LLC, New York, NY, USA). The following RCSB protein data bank (pdb) crystal structures were used for modeling studies: 1T8I, 3QX3, 5EK2, 5XE1, 6AZV, 6AZW. Each protein structure was initially prepared by standard settings of the Protein Preparation Wizard 2015-4 (Epik version 2.4, Schrödinger, LLC, 2015; Impact version 5.9, Schrödinger, LLC, 2015; Prime version 3.2, Schrödinger LLC, 2015). For energy minimizations of the small-molecule ligands, MacroModel (version 11.0, Schrödinger, LLC, 2015) was used. Ionization states and tautomers were generated with LigPrep (version 3.6, Schrödinger, LLC, 2015). Ligand docking and receptor grid generation was performed with Glide (version 6.9, Schrödinger, LLC, 2015). Figures and ligand interaction diagrams (LID) were generated by Maestro.

Supplementary Materials: The following are available online at http://www.mdpi.com/1660-3397/17/8/439/s1, HR-ESIMS and NMR spectra of compounds 1-6. ECD spectra of compounds 1,4,5, and $\mathbf{6}$.

Author Contributions: Design of the work, D.T. and F.L.; sample provision, D.J.; extraction, purifications of compounds, F.L.; data analysis, F.L. and D.T.; molecular docking experiment, C.P.; writing original manuscript, F.L. and D.T.; editing, D.T.; supervision, D.T.

Funding: This research received no external funding.

Acknowledgments: Fengiie Li thanks the China Scholarship Council for a Ph.D. fellowship. The Deutsche Forschungsgemeinschaft (DFG) is acknowledged by Dorte Janussen for financial support to her Antarctic sponge research (JA 1063/17-1). We thank Daniel Kersken for his dedicated effort in collection and fixation of these sponges during the PS96 expedition, thanks are due also to the captain and crew of RV POLARSTERN. We are grateful to Arlette Wenzel-Storjohann and Jana Heumann for performing anticancer assays. Joachim Grötzinger is acknowledged for offering the J-810 CD spectrometer for ECD spectrum measurement. We acknowledge financial support by Land Schleswig-Holstein within the funding program Open Access Publikationsfonds.

Conflicts of Interest: The authors declare no conflict of interest.

\section{References}

1. Alvarez, B.; Bergquist, P.R.; Battershill, C.N. Taxonomic revision of the genus Latrunculia du Bocage (Porifera: Demospongiae: Latrunculiidae) in New Zealand. N. Z. J. Mar. Freshw. Res. 2002, 36, 151-184. [CrossRef] 
2. Samaai, T.; Gibbons, M.J.; Kelly, M.; Davies-Coleman, M. South African Latrunculiidae (Porifera: Demospongiae: Poecilosclerida): Descriptions of new species of Latrunculia du Bocage, Strongylodesma Lévi, and Tsitsikamma Samaai \& Kelly. Zootaxa 2003, 371, 1.

3. Kelly, M.; Sim-Smith, C.; Stone, R.; Samaai, T.; Reiswig, H.; Austin, W. New taxa and arrangements within the family Latrunculiidae (Demospongiae, Poecilosclerida). Zootaxa 2016, 4121, 1. [CrossRef] [PubMed]

4. Capon, R.; MacLeod, J.K.; Willis, A.C. Trunculins A and B, norsesterterpene cyclic peroxides from a marine sponge, Latrunculia brevis. J. Org. Chem. 1987, 52, 339-342. [CrossRef]

5. Butler, M.; Capon, R.; Capon, R. Trunculin-F and Contrunculin-A and -B: Novel oxygenated norterpenes From a Southern Australian marine sponge, Latrunculia conulosa. Aust. J. Chem. 1993, 46, 1363. [CrossRef]

6. Zampella, A.; Randazzo, A.; Borbone, N.; Luciani, S.; Trevisi, L.; Debitus, C.; D'Auria, M.V. Isolation of callipeltins A-C and of two new open-chain derivatives of callipeltin A from the marine sponge Latrunculia sp. A revision of the stereostructure of callipeltins. Tetrahedron Lett. 2002, 43, 6163-6166. [CrossRef]

7. Sepe, V.; D'Orsi, R.; Borbone, N.; D'Auria, M.V.; Bifulco, G.; Monti, M.C.; Catania, A.; Zampella, A. Callipeltins F-I: New antifungal peptides from the marine sponge Latrunculia sp. Tetrahedron 2006, 62, 833-840. [CrossRef]

8. Perry, N.B.; Blunt, J.W.; McCombs, J.D.; Munro, M.H.G. Discorhabdin C, a highly cytotoxic pigment from a sponge of the genus Latrunculia. J. Org. Chem. 1986, 51, 5476-5478. [CrossRef]

9. Ford, J.; Capon, R.J. Discorhabdin R: A new antibacterial pyrroloiminoquinone from two latrunculiid marine sponges, Latrunculia sp. and Negombata sp. J. Nat. Prod. 2000, 63, 1527-1528. [CrossRef]

10. Hu, J.-F.; Fan, H.; Xiong, J.; Wu, S.-B. Discorhabdins and pyrroloiminoquinone-related alkaloids. Chem. Rev. 2011, 111, 5465-5491. [CrossRef] [PubMed]

11. Miller, K.; Alvarez, B.; Battershill, C.; Northcote, P.; Parthasarathy, H. Genetic, morphological, and chemical divergence in the sponge genus Latrunculia (Porifera: Demospongiae) from New Zealand. Mar. Biol. 2001, 139, 235-250. [CrossRef]

12. Furrow, F.B.; Amsler, C.D.; McClintock, J.B.; Baker, B.J. Surface sequestration of chemical feeding deterrents in the Antarctic sponge Latrunculia apicalis as an optimal defense against sea star spongivory. Mar. Boil. 2003, 143, 443-449. [CrossRef]

13. Reyes, F.; Martín, R.; Rueda, A.; Fernandez, R.; Montalvo, D.; Gomez, C.; Sánchez-Puelles, J.M. Discorhabdins I and L, cytotoxic alkaloids from the sponge Latrunculia brevis. J. Nat. Prod. 2004, 67, 463-465. [CrossRef] [PubMed]

14. Gunasekera, S.P.; Zuleta, I.A.; Longley, R.E.; Wright, A.E.; Pomponi, S.A. Discorhabdins S, T, and U, new cytotoxic pyrroloiminoquinones from a deep-water Caribbean sponge of the genus Batzella. J. Nat. Prod. 2003, 66, 1615-1617. [CrossRef] [PubMed]

15. Jeon, J.-E.; Na, Z.; Jung, M.; Lee, H.-S.; Sim, C.J.; Nahm, K.; Oh, K.-B.; Shin, J. Discorhabdins from the Korean Marine Sponge Sceptrella sp. J. Nat. Prod. 2010, 73, 258-262. [CrossRef] [PubMed]

16. Wada, Y.; Harayama, Y.; Kamimura, D.; Yoshida, M.; Shibata, T.; Fujiwara, K.; Morimoto, K.; Fujioka, H.; Kita, Y. The synthetic and biological studies of discorhabdins and related compounds. Org. Biomol. Chem. 2011, 9, 4959-4976. [CrossRef] [PubMed]

17. Goey, A.K.L.; Chau, C.H.; Sissung, T.M.; Cook, K.M.; Venzon, D.J.; Castro, A.; Ransom, T.R.; Henrich, C.J.; McKee, T.C.; McMahon, J.B.; et al. Screening and biological effects of marine pyrroloiminoquinone alkaloids: Potential inhibitors of the HIF-1 $\alpha /$ p300 interaction. J. Nat. Prod. 2016, 79, 1267-1275. [CrossRef]

18. Li, F.; Janussen, D.; Peifer, C.; Pérez-Victoria, I.; Tasdemir, D. Targeted isolation of tsitsikammamines from the antarctic deep-sea sponge Latrunculia biformis by molecular networking and anticancer activity. Mar. Drugs 2018, 16, 268. [CrossRef]

19. Antunes, E.M.; Beukes, D.R.; Kelly, M.; Samaai, T.; Barrows, L.R.; Marshall, K.M.; Sincich, C.; Davies-Coleman, M.T. Cytotoxic Pyrroloiminoquinones from four new species of South African Latrunculid Sponges. J. Nat. Prod. 2004, 67, 1268-1276. [CrossRef]

20. Delfourne, E. Analogues of marine pyrroloiminoquinone alkaloids: Synthesis and antitumor properties. Anti-Cancer Agents Med. Chem. 2008, 8, 910-916. [CrossRef]

21. Dolušić, E.; Larrieu, P.; Meinguet, C.; Colette, D.; Rives, A.; Blanc, S.; Ferain, T.; Pilotte, L.; Stroobant, V.; Wouters, J.; et al. Indoleamine 2,3-dioxygenase inhibitory activity of derivatives of marine alkaloid tsitsikammamine A. Bioorg. Med. Chem. Lett. 2013, 23, 47-54. [CrossRef] 
22. Wang, M.; Carver, J.J.; Phelan, V.V.; Sanchez, L.M.; Garg, N.; Peng, Y.; Nguyen, D.D.; Watrous, J.; A Kapono, C.; Luzzatto-Knaan, T.; et al. Sharing and community curation of mass spectrometry data with Global Natural Products Social Molecular Networking. Nat. Biotechnol. 2016, 34, 828-837. [CrossRef]

23. Perry, N.B.; Blunt, J.W.; Munro, M.H.G.; Higa, T.; Sakai, R. Discorhabdin D, an antitumor alkaloid from the sponges Latrunculia brevis and Prianos sp. J. Org. Chem. 1988, 53, 4127-4128. [CrossRef]

24. Perry, N.B.; Blunt, J.W.; Munro, M.H.G. Cytotoxic pigments from New Zealand sponges of the genus Latrunculia: Discorhabdin A, discorhabdin B and discorhabdin C. Tetrahedron 1988, 44, 1727-1734. [CrossRef]

25. Yang, A.; Baker, B.J.; Grimwade, J.; Leonard, A.; McClintock, J.B. Discorhabdin Alkaloids from the Antarctic Sponge Latrunculia apicalis. J. Nat. Prod. 1995, 58, 1596-1599. [CrossRef]

26. Grkovic, T.; Pearce, A.N.; Munro, M.H.G.; Blunt, J.W.; Davies-Coleman, M.T.; Copp, B.R. Isolation and characterization of diastereomers of discorhabdins $\mathrm{H}$ and $\mathrm{K}$ and assignment of absolute configuration to discorhabdins D, N, Q, S, T, and U. J. Nat. Prod. 2010, 73, 1686-1693. [CrossRef]

27. Kobayashi, J.; Cheng, J.-F.; Ishibashi, M.; Nakamura, H.; Ohizumi, Y.; Hirata, Y.; Sasaki, T.; Lu, H.; Clardy, J. Prianosin A, a novel antileukemic alkaloid from the okinawan marine sponge Prianos melanos. Tetrahedron Lett. 1987, 28, 4939-4942. [CrossRef]

28. Sternhell, S. Correlation of interproton spin?spin coupling constants with structure. Q. Rev. Chem. Soc. 1969, 23, 236. [CrossRef]

29. Choudhury, S.R.; Traquair, J.A.; Jarvis, W.R. New extracellular fatty acids in culture filtrates of Sporothrix flocculosa and S. rugulosa. Can. J. Chem. 1995, 73, 84-87. [CrossRef]

30. Makarieva, T.N.; Santalova, E.A.; Gorshkova, I.A.; Dmitrenok, A.S.; Guzii, A.G.; Gorbach, V.I.; Svetashev, V.I.; Stonik, V.A. A new cytotoxic fatty acid (5Z,9Z)-22-methyl-5,9-tetracosadienoic acid and the sterols from the far Eastern sponge Geodinella robusta. Lipids 2002, 37, 75-80. [CrossRef]

31. Kornprobst, J.-M.; Barnathan, G. Demospongic acids revisited. Mar. Drugs 2010, 8, 2569-2577. [CrossRef]

32. Gunstone, F.; Pollard, M.; Scrimgeour, C.; Vedanayagam, H. Fatty acids. Part 50. 13C nuclear magnetic resonance studies of olefinic fatty acids and esters. Chem. Phys. Lipids 1977, 18, 115-129. [CrossRef]

33. Grkovic, T.; Ding, Y.; Li, X.-C.; Webb, V.L.; Ferreira, D.; Copp, B.R. Enantiomeric discorhabdin alkaloids and establishment of their absolute configurations using theoretical calculations of electronic circular dichroism spectra. J. Org. Chem. 2008, 73, 9133-9136. [CrossRef]

34. Botić, T.; Defant, A.; Zanini, P.; Žužek, M.C.; Frangež, R.; Janussen, D.; Kersken, D.; Knez, Ž.; Mancini, I.; Sepčić, K. Discorhabdin alkaloids from Antarctic Latrunculia spp. sponges as a new class of cholinesterase inhibitors. Eur. J. Med. Chem. 2017, 136, 294-304.

35. Hooper, G.J.; Davies-Coleman, M.T.; Kelly-Borges, M.; Coetzee, P.S. New alkaloids from a South African latrunculid sponge. Tetrahedron Lett. 1996, 37, 7135-7138. [CrossRef]

36. Dijoux, M.-G.; Gamble, W.R.; Hallock, Y.F.; Cardellina, J.H.; Van Soest, R.; Boyd, M.R. A new discorhabdin from two sponge genera. J. Nat. Prod. 1999, 62, 636-637. [CrossRef]

37. Zou, Y.; Hamann, M.T. Atkamine: A New Pyrroloiminoquinone scaffold from the cold water Aleutian Islands Latrunculia sponge. Org. Lett. 2013, 15, 1516-1519. [CrossRef]

38. Litchfield, C.; Greenberg, A.J.; Noto, G.; Morales, R.W. Unusually high levels of C24-C30 fatty acids in sponges of the class demospongiae. Lipids 1976, 11, 567-570. [CrossRef]

39. Řzanka, T.; Sigler, K. Odd-numbered very-long-chain fatty acids from the microbial, animal and plant kingdoms. Prog. Lipid Res. 2009, 48, 206-238. [CrossRef]

40. Litchfield, C.; Marcantonio, E.E. Occurrence of 5,9,19-octacosatrienoic, 5,9-hexacosadienoic and 17-hexacosenoic acids in the marine spongeXestospongia halichondroides. Lipids 1978, 13, 199-202. [CrossRef]

41. Imbs, A.B.; Demidkova, D.A.; Dautova, T.N.; Latyshev, N.A. Fatty acid biomarkers of symbionts and unusual inhibition of tetracosapolyenoic acid biosynthesis in corals (Octocorallia). Lipids 2009, 44, 325-335. [CrossRef]

42. Thiel, V.; Blumenberg, M.; Hefter, J.; Pape, T.; Pomponi, S.; Reed, J.; Reitner, J.; Wörheide, G.; Michaelis, W. A chemical view of the most ancient metazoa-Biomarker chemotaxonomy of hexactinellid sponges. Naturwissenschaften 2002, 89, 60-66. [CrossRef]

43. Botic, T.; Cör, D.; Anesi, A.; Guella, G.; Sepčić, K.; Janussen, D.; Kersken, D.; Knez, Ž. Fatty acid composition and antioxidant activity of Antarctic marine sponges of the genus Latrunculia. Polar Boil. 2015, 38, 1605-1612. [CrossRef]

44. Boury-Esnault, N.; Rützler, K.; Ruetzler, K. Thesaurus of sponge morphology. Smithson. Contrib. Zool. 1997, 596, 1-55. [CrossRef] 
45. Samaai, T.; Gibbons, M.J.; Kelly, M. Revision of the genus Latrunculia du Bocage, 1869 (Porifera: Demospongiae: Latrunculiidae) with descriptions of new species from New Caledonia and the Northeastern Pacific. Zootaxa 2006, 1127, 1-71. [CrossRef]

46. Shannon, P.; Markiel, A.; Ozier, O.; Baliga, N.S.; Wang, J.T.; Ramage, D.; Amin, N.; Schwikowski, B.; Ideker, T. Cytoscape: A software environment for integrated models of biomolecular interaction networks. Genome Res. 2003, 13, 2498-2504. [CrossRef]

(C) 2019 by the authors. Licensee MDPI, Basel, Switzerland. This article is an open access article distributed under the terms and conditions of the Creative Commons Attribution (CC BY) license (http://creativecommons.org/licenses/by/4.0/). 